\title{
Training diagnostic skills for nuclear power plants
}

\section{Goodstein, L.P.}

Publication date:

1986

Document Version

Publisher's PDF, also known as Version of record

Link back to DTU Orbit

\section{Citation (APA):}

Goodstein, L. P. (1986). Training diagnostic skills for nuclear power plants. Risø National Laboratory. Risø-M No. 2587

\section{General rights}

Copyright and moral rights for the publications made accessible in the public portal are retained by the authors and/or other copyright owners and it is a condition of accessing publications that users recognise and abide by the legal requirements associated with these rights.

- Users may download and print one copy of any publication from the public portal for the purpose of private study or research.

- You may not further distribute the material or use it for any profit-making activity or commercial gain

- You may freely distribute the URL identifying the publication in the public portal

If you believe that this document breaches copyright please contact us providing details, and we will remove access to the work immediately and investigate your claim 


\section{DK 8700066}

NOVEMBER 1986

\section{TRAINING DIAGNOSTIC SKILS \\ FOR NUCLEAR POWER PLANTS}

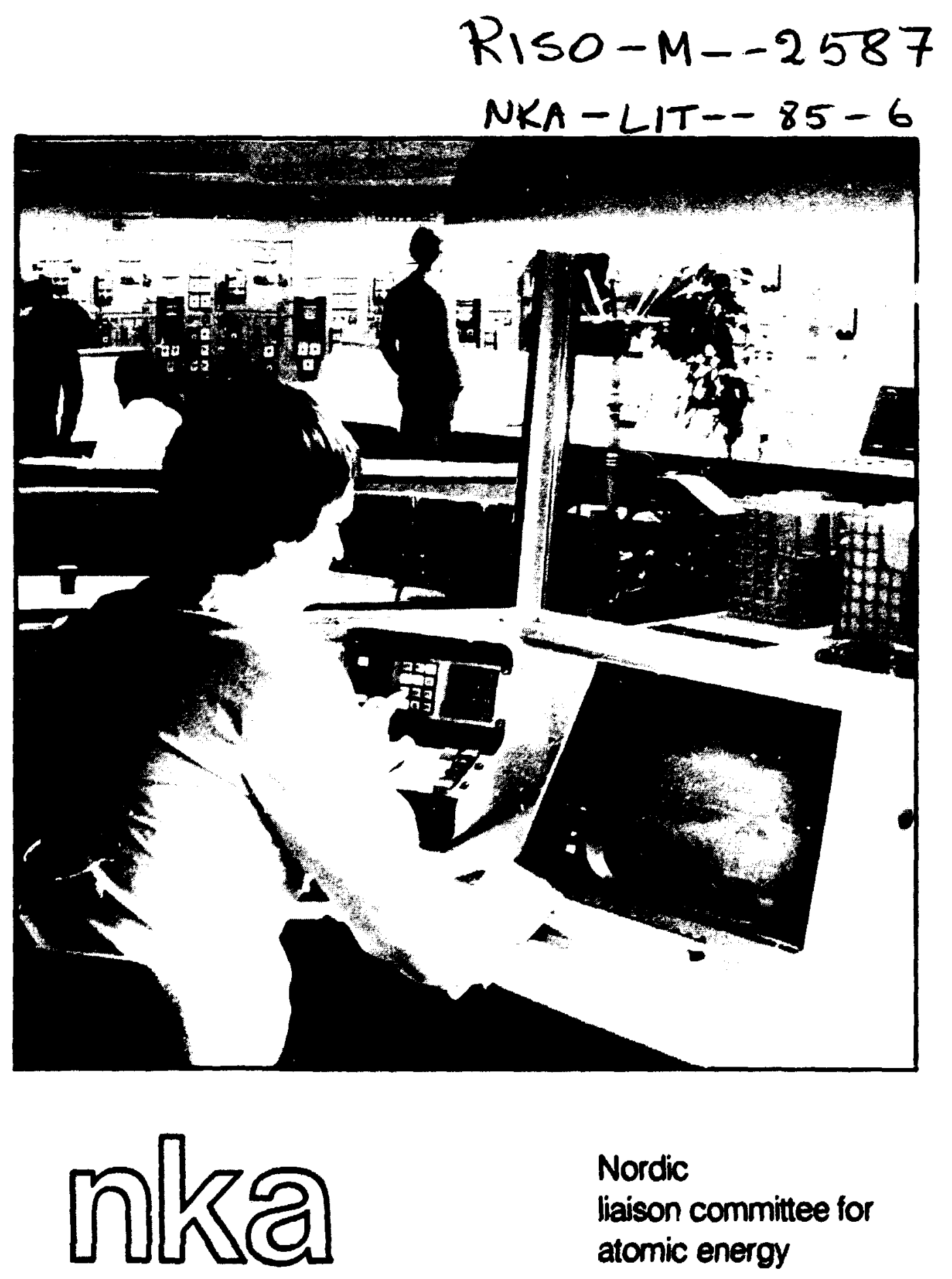




\title{
TRAINING DIAGNOSTIC SKILLS FOR NUCLEAR POWER PLANTS
}

\author{
Final Report of the NKA Project UT-4
}

Edited by:

\section{L.P.Goodstein}

Risø National Laboratory

Denmark 
TRAINING DIAGNOSTIC SKILLS

FOR NUCLEAR POWER PLANTS

cop. Nordisk Ministerråd, København 1987

ISBN 8773031097

Tryk: Aio-tryk, Odense

NORD $1987: 23$

NORDISK MINISTERRAD

Store Strandstræde 18

1255 København $K$.

t1f. (45 1) $1147 \quad 11$ 


\section{LIST OF CONTENTS}

\section{Page}

\section{ABSTRACT}

PREFACE

SUMMARY

i

SAMMENFATNING

vi i

1. INTRODUCTION

1

2. PROBLEM CONTEXT

3. PROJECT ACTIVITIES

11

3. 1 METHODS FOR TRAINING DIAGNOSTIC SKILLS 13

3.2 STUDY OF HUMAN ERRORS DURING SIMULATOR TRAINING 67

3.3 STUDY OF DIAGNOSTIC RULES BY INTERVIEWING OPERATORS 87

4. CONCL ,SIONS AND RECOMMENDATIONS 105

5. REFERENCES 109

6. LIST OF PROJECT REPORTS 113 
THE LIT STEERING COAITTEE

B. Wahlström*

L.P. Goodstein

M. Orreeide

J. Lindquist

F. Marcus

B. Liwång
Technical Reseatch Centre of Finland (VTT)

Riso National Laboratory, Denmark

Institute for Energy Technology, Norway (IFE)

The Swedish State Power Board (SV)

Nordic Liason Ccmittee for Atomic Energy (NKA)

Swedish Nuclear Power Inspectorate (SKI)

\section{LIST OF PARTICIPANTS IN THE LIT-A PROJECT}

Risø National Laboratory

Technical Research Centre

of Finland (VTT)

Imatran Voima Power Company

OECD Halden Reactor Project
J. Hedegârd

Jens Rasmussen* *

B. Wahlstrōm

L. Norros

P. Sammatti

S. Baker

E. Marshall

- Chairman

- Projectleader

Acknowledgement and thanks to the personnel and staff of AB Kärnkraftutbildning, Ringhals Nuclear Piwer Station and Loviisa Nuclear Power Stations for their help. 
ABSTRACT

Operators of large-scale industrial process plants such as nuclear power stations and chemical production plants are faced with a critical and complex task when confronted with disturbances in normal operation caused by technical failures or maintenance errors. Great care must be taken to prepare and support the operators during such situations. Procedural systems are provided, training un full-scale highfidelity simulators is often a prerequisite and decision-support systems are starting to be incorporated, especially in modern control rooms.

During recent years, it has become increasingly clear from "real-life" studies in complex production and transport industries that professional highly skilled troubleshooters can develop effective general purpose search strategies for locating and dealing with faults and, most importantly, with new and not previously experienced faults. This research has indicated that means for training of these general diagnostic abilities can be developed. In addition, other work has dealt with the problem of observing and analyzing operator behaviour in coping with disturbances. The NKA/LIT-4 project has continued these efforts in studying methods for training diagnostic skills as well as for observing and testing operator behaviour on training simulators.

INIS DESCriptorS: COMPUTERIZED SIMULATION; CONTROL ROOMS; NUCLEAR POWER PLANTS; HUMANFACTORS; TRAINING; NORDIC COUNTRIES.

This report forms part of the safety programme sponsored by NKA, the Nordic Liaison Committee for Atomic Energy, 1981-8. The work has been partly financed by the Nordic Council of Ministers. 


\section{PReface}

The safety of nuclear power, as for other complicated industrial processes, depends on an accurate and timely execution of tasks during the operation. There is, however, always the possibility that human errors either directly or indirectly initiate an unwanted course of events. The general aim is then to decrease the probability of human errors and to increase the probability of their detection. This is in principle made possible by a careful task design and by giving the human operator an appropriate training. This means in practice that one should consider the tools of the operator, the organization lie is working in, and the training he is given. All these aspects have been addressed in the Nordic LIT-research programme over the period 1981 to 1985.

The Nordic LIT-research programme has concentrated on.

- human errors in test and maintenance (LIT-1)

safety oriented organizations and human reliability (LIT-2)

- computer aided design of control rooms and plant automation (LIT-3.1)

- computer aided operation and experimental validation (LIT-3.2 and LIT-3.3)

- planning and evaluation of operator training (LIT-4).

These fields of research were selected from the experience of an earlier phase of the Nordic cooperation (cf. the reference Wahiström, Rasmussen, 1983).

The Nordic LIT-research programme involved a total effort of about 40 personyears of qualified researchers in Denmark, Finland, Norway and sweden. The research programme has been financed partly by project funds from the Nordic Council of Ministers and partly 
by funds from the different participating organizations. The LIT. research programme was initiated by the Nordic Liaison Committee for Atomic Energy (NKA) as a part of the Nordic cooperation in the field of safety in the energy production field. The following organizations have been financing and have also been directly involved in the LIT-research programme:

Rise National Laboratory, Roskilde, Denmark

Technical Research Centre of Finland (VTT), Espoo, Finland

Institute for Energy Technology (IFE), Halden, Norway

Swedish Nuclear Power Inspectorate (SKI), Stockholm, Sweden

Swedish State Power Board, Vällingby, Sweden

The LIT programme is reported in the following final reports:

The Human Component in the Safety of Complex Systems;

LIT programme summary report, NKA/LIT(85) 1

Human Errors in Test and Maintenance of Nuclear Power Plants -

Nordic Project Work; LIT-1 final report, NKA/LIT(85)2

Organizations for Safety; LIT.2 final report, NKA/LIT(85)3

The Design Process and the Use of Computerized Tools in Control Room Design; LIT.3.1 final report, NKA/LIT(85)4

Computer Aided Operation of Complex Systems; LIT $3.2 \& \quad 3.3$ final report, NKA/LIT(85)5

- Training in Diagnostic Skills for Nuclear Power Plants; LIT-4 final report, NKA/LIT(85)6 


\section{References}

Wahlström, B. and Rasmussen, J. (1983): Nordic Cooperation in the Field of Human Factors in Nuclear Power Plants. Conf. on Nuclear

Power Experience, IAEA Vienna, 1983, IAEA-CN-42/247, pp. 281-290. 


\section{SUMMARY}

Control room operators of large-scale industrial plants, such as nuclear power plants and chemical production plants, are often faced with a critical and complex task when disturbances occur because of component failures, maintenance problems, etc. Great care has to be taken to support the staff on such occasions; e.g., emergency procedures are prepared, training takes place on large-scale 'ıigh-fidelity simulators, appropriate aids are included in the control room, etc. Several of these aspects have been topics for the joint research programs sponsored by NKA.

The project LIT-4, discussed in this report, has been devoted to the study of methods for training diagnostic skills and for observing operators' diagnostic performance on training simulators. In recent years, it has become increasingly clear from studies in Denmark, the U.S.A. and the U.K. of diagnostic strategies used in "real-life" tasks within electronic maintenance, petro-chemical industries, aviation, etc. that professional, highly skilled trouble-shooters develop "know-how" and utilize search strategies which can be very effective but which are not based on formal theoretical knowledge of system operation. This research has indicated that effective methods for training of general diagnostic abilities can be developed from an identification of effective search strategies and an analysis of the knowledge required in the form of procedural rules and plant characteristics. Other studies have indicated that suitable observation and analytic tools can be useful for following and studying actual operator behaviour in diagnosing and further coping with transients during simulator training

The research results already available in the institutes participating in the joint Scandinavian program in terms of models of human information processing, human reliability, operator performance during emergencies, etc. appeared to give a promising basis for establishing projects to study the transfer of such results to Nordic training simulator centers.

The main results can be summarized as follows:

* a more concentrated and integrated training in diagnosis would significantly improve the crews' ability to treat disturbed plant states.

* operators should be given support in obtaining a clear "view of the whole" so as to enable them to select and use the appropriate procedures. 
* communication and cooperation among crew members can be a problem, especially in complex and critical situations. The ability to verbally mediate one's reasoning and actions should be promoted.

* operators who were given a diagnostic rule course were very satisfied with the structured method it gave for tackling disturbances for which few or no instructions were applicable.

* the instructors felt that diagnostic training should be an integral part of the operators' basic training. An important followup to the LIT4 project should be the development of suitable diagnostic training material and methods - for both theoretical and practical training.

* some of the results are being employed in the design of a training program for the OECD Halden NORS simulator.

As a general comment, the projects indicated the feasibility of a useful cooperation between nuclear power plant operations, training specialists and researchers. 


\section{SAMAENFATNING}

Operatorerne $i$ kontrolrum på store industrielle anlæg - f.eks., kernekraftværker eller kemiske fabrikker - står tit over for en kritisk og kompleks opgave, når driftsforstyrrelser opstår på grund af fejl $i$ komponenter eller vedligeholdelsen. Derfor er det påravet at stotte driftsstaben i sådanne situationer ved at udvikle nødprocedurer, udstyre kontrolrummet med avancerede stotteforanstaltninger, indfore et passende traningsprogam med brug af en stor, realistisk simulator, m.m. Flere af disse punkter har været emner for tidligere forskningsprogrammer i NKA-regi.

.IT-4 projektet, som beskrives i denne rapport, omhandler metoder til træning af diagnostiske færdigheder såvel som iagttagelse af operatorens diagnostiske optræden ved en træningssimulator. I de senere år har man $i$ Danmark og fiere andre lande udfort studier over de diagnostiske strategier som faktisk bliver brugt i virkelige situationer, f.eks. ved elektronisk vedligeholdelse, i den kemiske industri, $11 y$ 0.s.v. Her har man fundet ud af, at professionelle, højt-kvalificerede fejlfindere udvikler "know-how" og anvender søgestrategier, som er meget effektive, men som ikke normalt er baseret på teoretisk viden. Denne forskning peger på, at det er muligt at udvikle effektive metoder til træning af diagnostiske færdigheder. Dette kræver identifikation af hvilke sogestrategier, som kan anvendes samt en analyse af den nodvendige viden $i$ form af regler og anlegskarakteristika. Andre studier har påvist, at der foreligger egnede iagtagelscs-og andre analytiske varktøjer til at understotte undersøgelser af operatørens faktiske optræden ved træningssimulatoren.

I projektet har man undersogt, hvordan disse metoder virker når de overfores til nordiske træningscentre. I dette arbejde har man kunnet bygge pa tidligere NKA-samarbejde vedrorende modeller af menneskelig informationsbehandling, menneskelig pålidelighed og kontrolrumsdesign. Nogle af projektets resultater er med held blevet brugt i gennemforelsen af traningsprogrammet på NORSsimulatoren ved Halden-projektet. 
Projektets hovedresultater var:

- En koncentreret og integreret traning vedrorende diagnose vil medfore en vasentlig forbedring af operatorens muligheder for at håndtere unormale situationer på anlægget.

* Man bør sørge for, at operatoren kan få et klart helhedsbillede til at stotte sine valg og anvendelse af de bedste egnede procedurer.

* Kommunikation og koordination driftsstaben imellem er of te et problem - især i kritiske og komplekse situationer. Man bør derfor indfore træning $i$ at kunne formulere sig og mundligt forklare/begrunde sine ovelvejelser og handlinger.

* Operatorer, som fik et kursus i diagnostiske regler, var tilfredse med den strukturerede máde, de herved fik til at håndtere forstyrrelser, for hvilke der ikke forelå instruktioner.

* Instruktørerne mente, at diagnostisk træning bør integreres i operatørernes grunduddannelse. LIT-4 projektet bor opfyldes af udarbejdelsen af et egnet og tilpasset træningsmateriale såvel for de teoretiske som de anvendte dele af en traning angående diagnose.

LIT-4 projektet er et eksempel pa, hvordan et nyttigt samarbejde lader sig gennemfore mellem industriens driftspersonale, træningsspecialister og forskere. 


\section{IMTRODUCTION}

The NKA/LIT project on human reliabity included work on computeraided design and operations of complex systems. A complementary area which became the subject of a separate activity (LIT-4) dealt with the planning and evaluation of operator training. The work is described in this report.

The project was an Nordic extension of an earlier international effort (International Evaluation of Operational Practises (IEOP)) with participation from the USA, France, Germany and Scandinavia. This cooperation aimed at establishing and testing methods for observing and evaluating operator behavior on training simulators.

The problem area was relevant in that the various Nordic participants had national interests which complemented each other rather nicely. Finland and Sweden each has an active nuclear program including operator training programs using full-scale simulators. Earlier cooperative efforts between VTT and Imatran Voima in Finland and with AKU in Sweden had indicated the value of gathering and analyzing data on operator performance and human errors and drawing conclusions on the implications for training. In addition, the OECD Halden Reactor Project in Norway was planning the estatlishment of an experimental control room for their new Pull-scale PWR simulator and was interested in designing and implementing a training program. At Ris $\varnothing$ in Denmark, there was an interest in the identification of generally useful diagnostic rules and strategies which operators could use under disturbed conditions in the plant. in particular, with regard to this project, the training of such rules was particularly relevant as was the verification of their usefulness in practice.

\section{Thus the main goals of LIT4 were:}

- the development and testing of methods for systematically observing, analyzing and interpreting operator performance during training. 
- the development and testing of training methods and contents for example, the need for specific vs general knowledge.

Project tasks included:

- developing of a theory and methods for acquisition of data from training simulators.

- planning and carrying out of experiments on training simulators at AKU (Sweden) and Loviisa (Finland).

- feed back the results in order to evaluate the actual training before the experiments, the form of training program and methods in a more general way as well as the training contents.

- utilize the results in the design of the training program for the operators of the new control room of the Halden NORS simulator.

In practice, there were three sub-projects.

Risø together with the Swedish State Power Board (in particular, the Ringhalls nuclear power station) and AKU, the Swedish training center, cooferated in an activity on "Methods for training of diagnostic skills".

VIT together with personnel from the Loviisa NPP (operated by Imatran Voima) did a study of "Operator errors during simulator training".

A "Study of the generation of diagnostic rules by interviews of operators" was performed by the OECD Halden Reactor Project in cooperation with Imatran Voima. 
These three projects are further described in this report. National reports which give more detailed information will be available shortly. 


\section{Problen comtext}

The operation of a technical system usually has two main goals:

- Production goals which relate to the result of the s;stem operation, of ten in economic terms. The ajor concern here is to run the technical system in such a way that the optimum production results and operating costs are achieved.

- Safety goals which concern the safe operation of the technical system from human and environmental points of view. Here the onus is here placed on the prevention of damage to technical system staff, third parties and environment.

These two goals are mirrored in the practical man-machine interface situations by operating instructions, established practices and sometines even national and international laws and regulations. These instructions etc. are imposed on the technical system staff in two ways: officially, by stating wiat is required during systea operation, and unofficially, by influencing attitudes towards routine and abnormal system opsration. The former refers to operation actions laid down by the instructions and during training etc. while the latter stems from what is desired :hen the instructions are applied to practical situations. The desirable way of applying instructions is partly determined by formal and informal directives issued by the management of the technical system and partly influenced by norms and established practice within natural groups of the staff. Thus, existing operator goals are results of a combination of formal and informal influences originating from both responsible authorities and operators' colleagues. From these goals, detailed inst,ructions and established practices respectively are derived and implemented in the routine operation of the technical system. As this operation can include known and foreseeable situations as well as unknown and unforeseeable situations, four different types of goal descriptions are possible: 


\author{
Known and fore- \\ seeable situa- \\ tions \\ Unknown and unfore- \\ seeable situations
}

$\begin{array}{ll}\text { Formal } & \text { Stated in de- } \\ \text { goals } & \text { tailed instruc- } \\ & \text { tions }\end{array}$

Informal

Provided by more

goals
Stated in general instructions ie.s. general priorities and procedures;

Have to be deterained by individual staff nembers or groups of staff newbers when the situations occur

The significance and "message" of this representation is at least three-fold: first, only general instructions covering formal goals can be given for unknown and unforeseeable situations. These general instructions, for obviuus reasons, lack details about the nature of situations for which the instructions are applicable. In such cases safety goals tend to receive higher priorities than production goals due to the unpredictability of situation cause and development.

Therefore, the instructions therefore usually attempt to state how to bring the technical system to "safe conditions" in such a way that all conceivable threats to the system are overcome. In the majority of unknown situations this is equal to a shut-down of the system which means that production is interrupted. This, in turn, can impose a goal conflict on the operators of the system: or. the one hand the staff is uncertain about the unknown situation and is therefore inclined to follow the general instruction which, although not directed towards a specific situation cause, is supposed to cure all kinds of situations. 
On the other hand, the staff is loyal to the primary reason for their interiace with the technical system, i.e. to keep up production and put professional pride into its continuus and traible-free operation. Seconcly, as the operaticn of technical systems cannot be coapletely covered by instructions, some situations will be dealt with by the operators according to the their goal interpretation. Thirdly, in situations in which they have to perfor a goal interpretation without instructions, the cutcone of the situation is entirely dependent on the capabilities of the operators, both as individuals and as a grcup.

The practical aspects of man-machine interface goals can therefore be sumarised in the following way:

- In ths absolute majority of operation situatior.s, formal goals and detailed instructions are available to the operators.

- More or less detailed establisned practices are implemented by the operators in two principal types of circumstances: as guidance complementary to the formal goals and instructions when the latter are incomplete in known and foreseeable situations and as major guidance when no goals and instructions are available in the same kind of situations.

- In the case of unknown situations, general goals and instructions are required for use by the operators. The technical systea is normally brought to complete or partial shut-down conditions due to safety goal related priorities.

- The operators have to determine informal goals and guidance on their own in cazes of unknown and unforeseeable situations, especially if the formal goals and instructions are incomplete and/or produce inappropriate results.

- Ambiguity and goal conflict can ocrur in a small number of cases when the operators have to supplement incomplete formal goals or determine goals in the absence of formal ones. 
Experience of, for example, the process industry shows that formal goals and instructions supplemented by established practices cover close to 100 per cent of normal, slightly disturbed or trivial operation situations. In most of the very few cases of seriously disturbed or emergency situations the technical system has been successfully brought to safe conditions according either to general formal directives or to goals and procedures determined by the operating staff. In the remaining extremely few cases of disturbed or emergency situations, the staff has been unable to solve the problem situation and accident has resulted.

\section{IMPLICATIOMS FOR TARIMIMG}

With this background in mind, snme implications for operator training and its evaluation can be derived.

Operator training strives after the development of the necessary resources for coping with situations calling for behavior at the skill, rule and knowledge-based levels; that is, supplying the operator with an approriate repertoire of behaviors for both routine/familiar as well as unexpected situations. Distinctions between the named categories of behavior give rise to three phases in attaining skilled performance - the early or cognitive phase, the intermediate or associative phase and the final or autonomous phase (which correspond closely to the knowledge, rule and skill categories). The problew in the control room is that there probably will be variable resources available to cope with the wide repertoire of situations as the result of the different amounts of training in the various phases which can be achieved.

An important consideration also is that training does not cease after the formal training courses - but continues in a very effective wanner in the "on-the-job" wode. This can create problems in that important but rarely used rules, associations, data patterns can be forgotten and/or confused with corresponding sets which can be generated "on-line" to cope with the more ramiliar situations. 
Operators have little chance for developing effective empirical rules for infrequent occurrences and, as stated above, specific work instructions can not be preplanned for all possible situations. Furthermore, it has been demonstrated (from the ThreeMile Island accident) that instructional systems for major designbase accidents will not necessarily cover less critical situations. Consequently, much importance must be placed on the operator being able to function is the knowledge-based domain and generate the necessary rules ad-hoc in the actual situation. Thus two of the LIT-4 sub-projects investigated various forms for training support for general-purpose diagnosis.

Another implication is the need for generating a feedback to training planners and others concerning the effectiveness of the implemented training. Thus, continuing the efforts of the IEOP program mentioned earlier, the project included two observation and analysis activities - one at the AKU simulator and the other at the Loviisa simulator. One of these attempted to ascertain the effects of training diagnostic rules and the other was concerned with identifying and classifying the types of operator errors which occurred. 


\section{PROJECT ACTIUITIES}

The three LIT-4 projects are described in the following sections. The projects were:

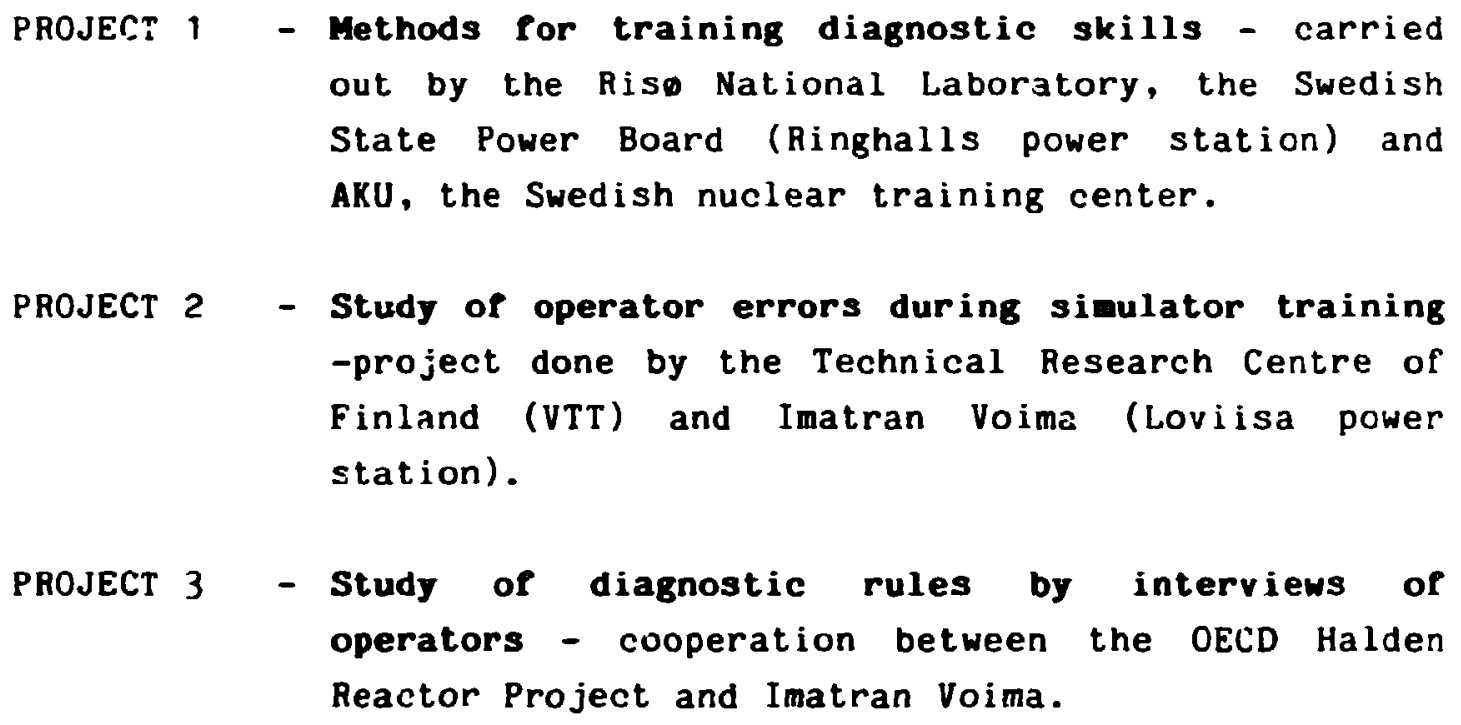




\subsection{METHODS FOR TRAINING DIAGNOSTIC SKILLS}

Generalized Strategies for State Identification and Diagnosis

Diagnosis can be considered as an information processing activity which can become quit. complex when diagnosing disturbances in technical systems. Thus it is convenient to describe the related human data processing in terms of data, the mental representations of the information describing system state, models representing the system's structure and/or function and strategies which relate overall goals to sets of models, data and tactical process rules. The objective of a diagnostic search may vary; to protect the plant, to compensate for the effects of a fault, to restore normal state, etc. To be able to support and train operators in this task, it is necessary to study the diagnostic strategies which are actually used in different situations. From this, one can generalize and formulate a set of strategies which can be used as the basis for system design, training, etc. In addition, it is important to discover the subjective preferences and performance criteria which guide the choice of and shifts between the strategies to be used in a specific situation.

In general, the diagnostic task in the present context is a search to identify and deal with a change from normal or planned operation in terms which can refer the controller to appropriate control actions.

A set of observations representing the abnormal state of the system - a set of symptoms - can be used as a search template in accessing a library of symptoms related to different abnormal system conditions to find a matching set. This kind of search will be called symptomatic search. On the other hand, the search can be performed in the actual, maloperating system with reference to a template representing normal or planned operation. The change will then be found as a mismatch and identified by its location in the template. Consequently, this kind of search strategy is called topographic search. 
The difference between the two kinds of search strategies is related to a basic diffeience in the use of the observed information. Every observation implies identification of an information source and reading of the content of the message. In symptomatic search, reference to the identity of system state is obtained from the message read; in topographic search, reference is taken from the topographic location of the source, while the messages are subject only to good/bad judgement which are used for tactical control of the search.

\section{Topographic Search}

The topographic search is performed by a good/bad mapping of the system through which the extent of the potentially "bad" field is gradually narruwed down until the location of the change is determined with sufficient resolution to allow selection of an appropriate counteraction. The domain or level of thinking in which the search is performed will vary. The search can be performed directly in the physical domain but, in most cases, the search is a mental operation at a level of abstraction which depends upon the immadiate goal and intention of the controlier and upon the form of the reference map or model available. Also the resolution needed for the final location depends upon the actual circumstances.

The topographic strategy is illustrated by the information flow graph of Fig.1. The main elements of the strategy which will be considered in more detail are the model of system used to structure the search, the kind of data used to represent the actual, failed plant state and the normal, reference state and, finally, the tactical process rules used to control the search sequence.

The topographic search is performed as a guod/bad mapping of the system which results in a stepwise limitalion of the field of attention within which further search is to be considered. The search depends on a map of the system which gives information on 


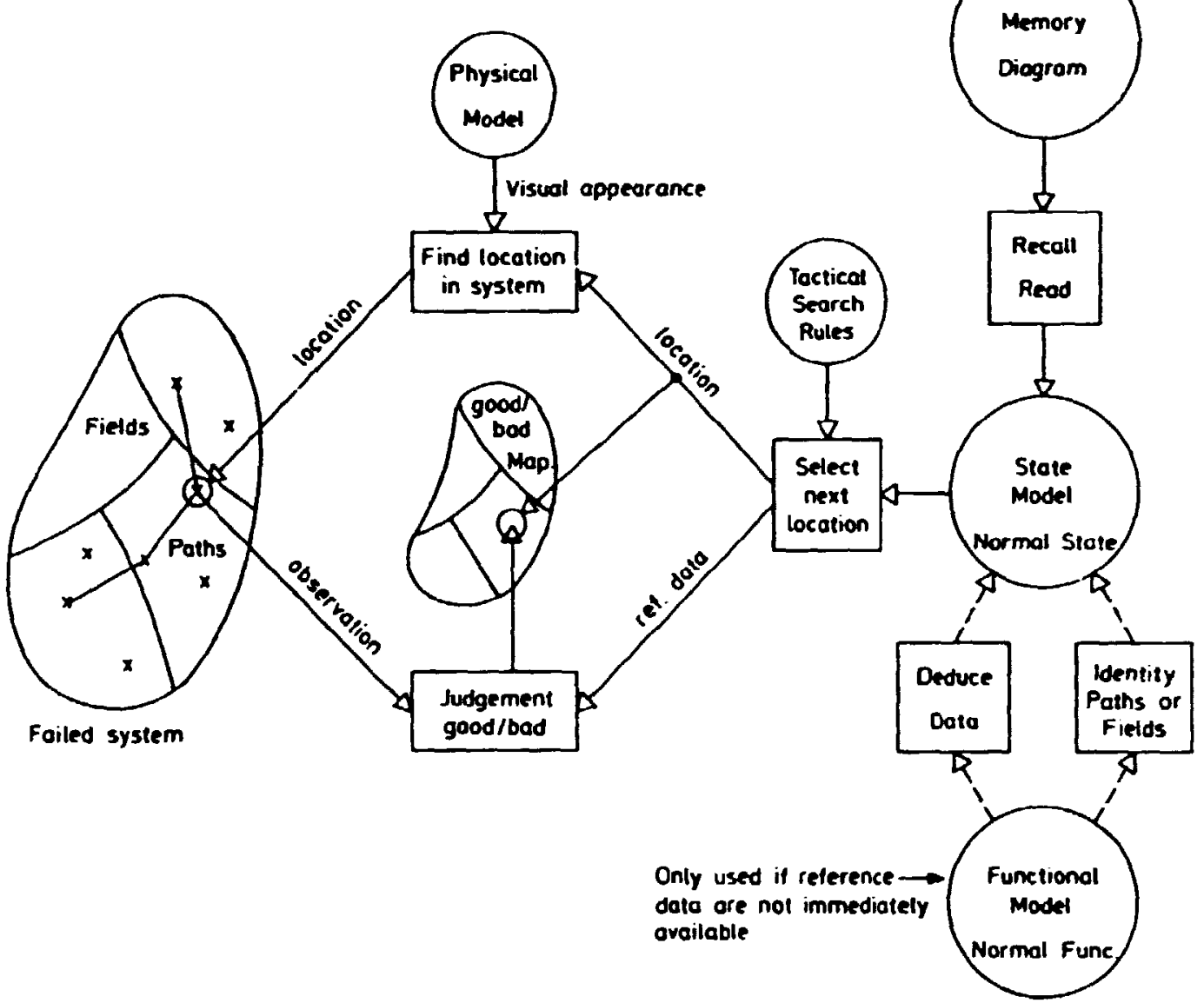

Figure 1 Information flow map illustrating the topographic search strategy, which is based on good/bad judgements of variables along a path or of patterns related to a field. 
the location of sources of potential observations for which reference information is available for judgements. The map is a model which identifies the potential sources of observations relative to the topology of the physical system itself, of its internal anatomical or functional structure, or of its external purposes.

The search sequence is based on a set of, of ten heuristic, rules serving to limit the necessary field of attention. If different external functions can be related to separate internal parts or subsystems, a good/bad scan of external functions effectively identifies the internal field for further search. If a faulty input/output relation is found, the related causal route should be searched, e.8., by the half-split heuristic, etc. In the pure form, the tactical search decisions are based exclusively on the one bit of information obtained from the good/bad judgement of the individual observations.

The information available in observations is used rather uneconomically by topographic strategies, since they depend only upon good/bad judgements. Furthermore, they do not take into account previously experienced faults and disturbances. Therefore, switching to other strategies may be necessary to reach an acceptable resolution of the search or to acquire good tactical guidance during the search. However, the topographic search is advantageous because of its dependence upon a model of normal plant operation - which can be derived during design or obtained by data collection during normal operation. Therefore, consistency and correctness of the strategy can be verified and, since it does not depend on models of malfunction, it will be less disturbed by multiple or "unknown" disturbances than strategies based on symptoms. 


\section{Symptomatic Search}

Symptomatic search strategies are based on the information content of observations to obtain a direct. identification of the system state, instead of the location of the information source in a topographic map. The search decisions are derived from the internal relationship in data sets and not from the topological structure of system properties. In principle, a search is made through a set of abnormal data sets, symptons, to find the set which matches the actual observed pattern of system behaviour. The reference patterns can be collected empirically from system maloperation or derived by analysis or simulation of the system's response to postulated disturbances. Furthermore reference patterns can be generated on-line if the contr, ler has a functional model available which can be modified to match a current hypothesis about the disturbance.

When the diagnosis is performed in the date domain by a sear h through a library of symptom patterns, it has no logical relation to system function. The result is directly the label of the matching symptom pattern which may be in terms of cause, effect, location or the appropriate control action itself. Depending upon the structure of the controller and its memory, the search can be a parallel, data driven pattern recognition, or a sequential decision table search as illustrated by Fig.2.

Pattern recognition plays an important role in human diagnosis; it can efficiently identify familiar system states and disturbances directly, but it is also used frequently during topographic search to guide tactir.l decisions. Recognitions are then typically based on more fuzzy or general reference symptoms in terms of generic fault patterns referring to types of function or physical parts, such as noise characteristics, instability or forms of nonlinearity.

Decision table search depends upon a set of tactical rules to guide the search which can be based on probability of occurrence, a hierarchical structuring of the attributes (like Linne's generic 


\section{PATTERN RECOGNITION}

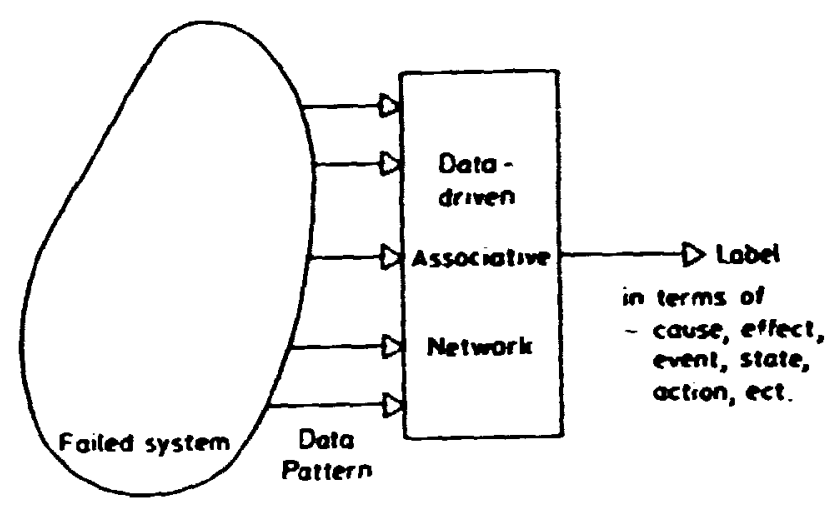

\section{DECISION TABLE SEARCH}

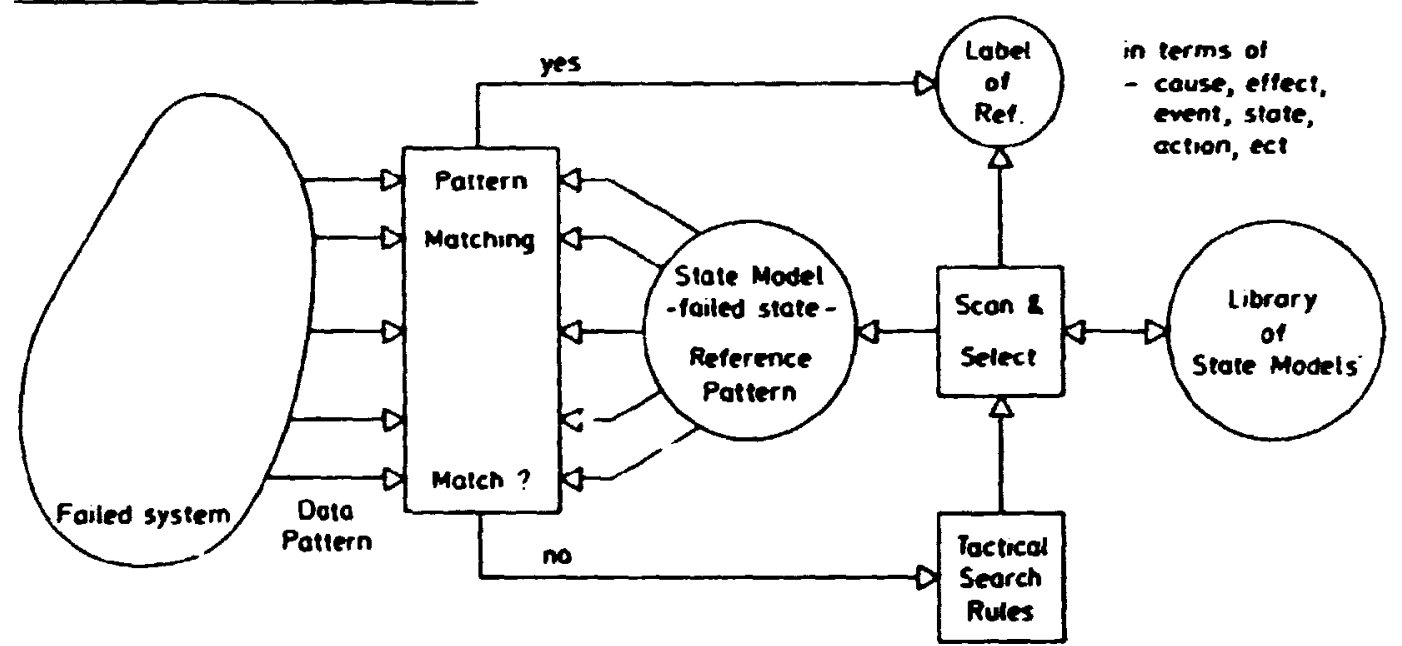

Figure 2. Information flow maps for symptomatic diagnosis based on pattern recognition or search through a library of symptoms. 
system for botanical identification as used in field guides), or functional relations, stored as fault trees, etc. Human diagnosticians probably would use decision tables for verification of more ambiguous recognitions.

If a search is based on reference patterns generated "on-line" by modification of a functional model in correspondance with a postulated disturbance, the strategy can be called search by hypothesis and test as illustrated in Fig.3. The efficiency of this type of search depends upon the tactics of generating hypotheses. Typically, in human diagnosis, hypotheses result from uncertain topographic search or fuzzy recognitions.

Symptomatic search is advantageous from the point of view of information economy, and a precise identification can frequently be obtained in a one-shot decision. One serious limitation will be that a reference pattern of the actual abnormal state of operation must be available, and multiple faults and disturbances must be considered. This means that reference sets must be prepared by analysis or recorded from prior occurrences. Or, the reference sets can be generated on-line by means of a functional model of the system which can be modified on occasion to simulate the abnormal system state in accordance with the current hypothesis.

The differences in resource requirements for the different strategies are illustrated in Fig.4. Thus, in practise, the choice of strategy will usually be based on an "available resource" vs "demand" match.

\section{Diagnostic Search Strategies and Diagnostic Rules}

Tactical search rules, when used for diagnostic purposes, can in principle be of two different types: algorithms and heuristics. 


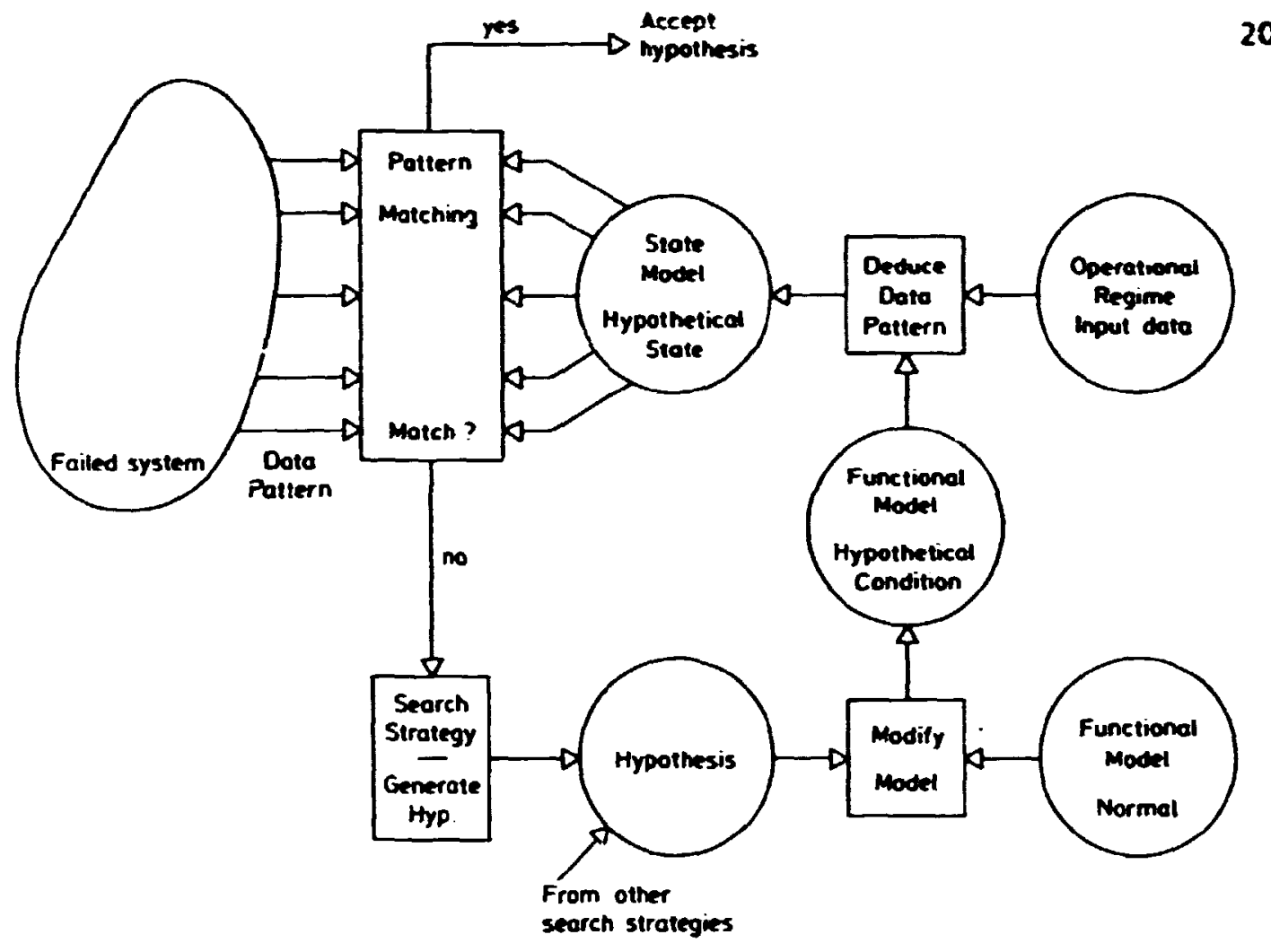

Figure 3. Information flow map for symptomatic search by hypothesis and test. The figure illustrates a conceptual test. In practice, the test may be performed by correcting the system according to the hypothesis and test for normal, instead of modifying the model as shown.

\begin{tabular}{|c|c|c|c|c|}
\hline PERFoRmance raCtoR STrategY & $\begin{array}{l}\text { TOPOGRAPHIC } \\
\text { SENACH }\end{array}$ & RECOCNITION & $\begin{array}{l}\text { OECision } \\
\text { TABCE }\end{array}$ & $\begin{array}{l}\text { HXPOTHESIS } \\
\text { AND TEST }\end{array}$ \\
\hline TIME SUENT & - & Lom & - & - \\
\hline NUMBER OF OASERVATIONS & MIGH & Low & - & Low \\
\hline OEPENDEMCY ON PATTERM PERCEPTION & - & HIGH & - & - \\
\hline LOAD UPON SHORT TERY MEMORY & LON & LON & HICH & MICH \\
\hline COMPLEXITY OF COGNITIVE PROCESSES & Low & LOW & - & HICH \\
\hline COMPLEXITY OF FUNCTIONAL MODEL & LON & - & - & HIGH \\
\hline GEMERAL APPLICABILITY OF TACTICAL RULES & HICH & - & - & LOW \\
\hline DEPENDENCY ON MALYUACTION EXPERIENCE & LON & HICH & - & Low \\
\hline DEPENDENCY ON MALTUMCTION PRE-AMALYSTS & - & - & HIGH & - \\
\hline
\end{tabular}

Figure 4. The table illustrates the difference in resource requirements of the various diagnostic strategies which makes possible a resource/demand matching by proper choice of strategy. Features not filled in are either not typical, being dependent on circumstances, or not relevant. 
The former are defined as:

Rules which when executed in the appropriate sequence, either produce a solution or terminate at a defined failure point.

This means that, when applying a set of algorithas to a problem, either a solution is found or the search finished at a predetermined point; i.e.. the correct diagnosis will result every time the appropriate algorithas are used.

As opposed to this straightforward type of rule, the heuristic tactical search rule is defined as:

A personal guiding instrustion for managing information processing and the appropriate action to be carried out in diagnosing the present state of a system.

Here there is no guarantee that the application of the rule will automatically lead to the solution of the problem. The rule will only function as a support when, for instance, trying to diagnose a disturbance within a technical system. Since this type of rule will be examined in connection with the diagnosis of plant state in the LIT-4 empirical investigation, it will be called a diagnostic rule.

It is obvious that an operator will face and use both types of rules in his everyday practical work with the technical system. In a very general and rough way, one might say that the operator is constantly trying to discover algorithms amongst the heuristic rules he applies. When an algorithm is found in this way, it can then, for instance, be formulated as an instruction for dealing with the technical system. Even though this is important for diagnostic purposes, the search situations containing algorithms will not be included in the following discussion. As a consequence, when discussing search strategies and diagnostic rules, these terms refer to heuristics only. 
Each search strategy has in principal its corresponding diagnostic rules in a specific search situation. When carrying out a search within a technical systea according to a certain strategy. a typical set of diagnostic rules are used by the operators. However. as pointed out in the definition of diagnostic rules. these are "personal guiding instructions": therefore the individual operator will add his oun rules to the set of coman rules for each strategy. Thus the diagnostic rules within a certain search strategy consist of a core of rules used by all operators plus a set of individual rules which might vary from operator to operator.

This classification will later be put into a practical ontext. namely in the construction of diagnostic rules for use in nuclear power station disturbances.

\section{Situations In Which Diagnostic Rules Can Be Used}

The situations in which operators experience uncertainty in disturbed system states have previously been mentioned in this paper. This uncertainty stems from the fact that the operators have no guide-lines, the application of which would entirely resolve the disturbed situation. Instead, they have to approach the disturbance using methods which cannot guarantee high solution success rates. Thus, systematically constructed and applied heuristic diagnostic rules can support operators of technical systems in the following situations:

a. When a deviation from normal indications has just started.

In such a situation, instructions are seldom available. As it is often best to treat a disturbance as soon as possible, the operators regard a systematic method for data collection as especially useful. The disturbance has, in such a case, not yet developed sufficiently to influence all parameters, which means that a complete symptom picture may not be available. It is therefore imperative to prevent hasty decisions and "jumping to conclusions". 
b. When the syeptons of the disturbance cause are not covered by instructions.

In this situation. the operators face syaptoms which are not, or are only partially, covered by instructions. As mentioned earlier. this emphasises the importance of structured and thorough data collection and a clear awareness of the over-all symptom picture. The potential danger of "fitting-in suitable information" in order to get the "right" characteristics for a certain disturbance cause is especially important in these circumstances.

c. When there is uncertainty about which of wany alternatives is the correct or the important one.

In this case the operators require adequate data in order to discriminate between the correct or more probable alternative and the other ones. This demands an overview of what the alternatives consist of as well as a selection of data within each alternative in such a way that the correct or more probable alternative can be identified. The manner of using and combining data is crucial and highlights the importance of acquiring relevant bits of information while neglecting unimportant data.

d. When external and other factors disturb or negatively influence the disturbance treatment.

Such factors aggravate the disturbance treatment by interrupting the operators' detection process or by decreasing their efficiency in these processes. Examples of the latter are operator coordination insufficiencies, operators dispatched to other tasks in or outside the control room.

Furthermore, stress, caused by a rapidly developing disturbance for example, or subjectively induced by the operators' strong desire to solve and quickly correct the disturbance, puts a strain on the accuracy of disturbance treatment. Therefore, the operators need a clear procedure which they can follow and return to when interruptions occur. 
The practical iaplementation of heuristic diagnostic rules in technical disturbance procedures requires a nunber of considerations, such as operator training aspects, coordinations of these rules with instructions and operator team utilization aspects. Some of these considerations are discussed later in this paper.

Types of Diagnostic lules

Diagnostic rules can be organized on a scale ranging from general to specific. A possible classification is shown below:

Type or rule

Plant non-specific

Plant specific

System specific
General

Operational

\section{Classification}

Specific
Definition

Independent of

- type of plant

- type of process

Independent of process but dependent on plant (e.g. nuclear processes) Dependent of both plant and process

In addition, rules can be aimed at supporting specific phases of the problem solving/decision making sequence - e.g., observation, identification, evaluation, task definition, etc.

\section{Diagnostic Rules as Part of the Diagnostic Search}

When a disturbance occurs in a technical system, it constitutes a threat to or a deviation from the purposes of the technical system. The goal of the operator is therefore to handle the disturbance in an appropriate way. This includes identification of the source(s) of the disturbance and a rectifying action. To be 
able to carry out these two activities, the operator has to assess the nature of the disturbance, i.e. to "diagnose" the characteristics of the disturbance. This is done by searching within the technical system and the whole procedure is called a diagnostic search supported by diagnostic rules. Such support will require that the diagnostic rules

- cover sufficiently the entire diagnostic search sequence.

- imply methods for putting priorities on different parts of the information available.

To fulfill these two criteria, the diagnostic rules have to be adapted to the various stages within the diagnostic search. As diagnostic search is a problem solving procedure, the basis for this adaptation is the problem solving sequence itself. Thus the different steps within the problem solving sequence have their corresponding steps in the diagnostic search sequence and will be called diagnostic phases. Each diagnostic phase has a number of diagnostic units which correspond to the decisions within each step of the problem solving sequence. Finally, each diagnostic unit contains the smallest part within a diagnostic search sequence which is the diagnostic rule as such.

With the heuristic approach, the method in itself only describes the way in which to use the available information in order to reach the solution; as a result the diagnostic search sequence has to be linked up with the information required to carry out the diagnosis. There are therefore two main aspects of such a search sequence; the informative aspect, which refers to the information necessary to perform the search (technical data, knowledge about the system and its behaviour etc.) and the procedural aspect, which refers to the heuristic method itself. 


\section{Construction of Diagnostic Rules}

The definition of the target training group and its needs for diagnostic training are used as starting points in the construction of sets of rules to be used during training. The construction sequence could be carried out as follows:

\section{Data collection concerning desired behaviour repertoire}

Having determined the area of interest for diagnosis, contacts are made with responsible representatives and crews at an appropriate nuclear power station in order to obtain permission to carry out the data collection. ruring these contacts, the same considerations as discussed above concerning training initiative and motivation should be borne in mind. The outcome of the diagnostic rule construction is highly dependent on this stage and it is therefore vital that the data collection results mirror normal conditions as far as possible. The data collection is then performed using one of a variety of methods or combinations of, for example, interviews or observations. If the person carrying out the data collection is not completely familiar technically with the system in question, a second person with such knowledge should assist during the collection of data.

Only the situations in which the observed or interviewed crews have made correct diagnoses and adequate rectifying actions are considered for the subsequent construction of diagnostic rules. It is essential that collected data covers as many aspects of the diagnostic situation as possible. Each stage of the diagnostic seqence should be considered several times in order to catch nuances in the way the crews handle them. After each individual observation or interview, a rough evaluation of the data collected can be made in order to establish how weil the different stages have been covered. This evaluation points to those areas which are deserving of concentration during the next observation or interview. 


\section{Outlining the first version}

Basic data from the cullection are organised initialiy by stating the respective diagnostic phases. In general, these are the same as the main stages in the search which are themselves based on logical steps in fault finding activities. It is therefore likely that the observed situation can be structured according to the general search sequence, at least initially until the data give other impulses. Under each diagnostic phase, headline data are reformulated into statements based on what was observed. These statements are short sentences describing a certain search activity carried out by the observed or interviewed crews. The next step is to look for similarities between and common patterns among the statements. Similarities are assumed to show fruitful search actions and patterns indicate among other things sequential events during the fault linding activity. The basic assumption is that the more similarities and patterns, the stronger indication of successful search activities. Similar statements are grouped together under each phase headline and arranged in an order corresponding to the patterns. A statement covering the other statements in each group is picked out and used as a headline labelling the diagnostic unit. The remaining statements in each diagnastic unit are now scrutinised from a qualitative point of view. From statements covering the same diagnostic element, the most complete is picked out. The principle is to obtain sequential statements which seem to describe the totality of the respectivs diagnostic unit. When all units are organised the complete diagnostic sequence is put together to form the first version.

This version has nriw to be evaluated by a group of professionals having extensive experience with diagnostic searches in the same type of nuclear power station as used for the data collection. Their task is to judge the informative value of the first version as regards logic and coverage of the diagnostic rules within the sequence. All comments are noted during the discussion and later reviewed to check their relevance. There are great advantages at this stage in testing the diagnostic rules in a simulator by following the transient's development parallel to the application 
of the rules and at the same time noting the professionals' comments.

\section{The second version}

Comments obtained from the evaluation of the first version are now taken into consideration for further refinement resulting in a second version. If the reference group regarded some parts of the sequence as incomplete, it might be necessary to collect more data through observation or interview as before. Even those statements previously excluded could be used if the reference group gives indications which seem to justify their inclusion. After modifications are made, the complete second version is ready to be tested in practical circumstances, frequently in full scale simulators.

\section{Testing of the second version}

Control room crews at the same or an identical nuclear power station should be involved in testing the second version. In principle two types of methods can be used to evaluate the rules and their interaction with the operators' handling of disturbances - subjective comments via questionnaires, interviews, etc and/or observation by instructors or other experts. One can use control groups (who do not receive special training in diagnostic rules) and compare their performance with an experimental group which has received special instruction. In addition, one has to select an appropriate set of transients on the simulator for which the crews' performance will be evaluated.

The possibilities for various test procedures are of course numerous. The main points in all test variants are: to obtain opinions about the usefulness of the rules, their logical order and the degree to which they cover the transients. By using crews who have not received training in diagnostic rules, it 
is possible to check various aspects of transients exercised in the simulator, e.g. degree of difficulty, realism etc.

\section{Modification of the second version}

From the results of the test of the second version, at least three conclusions can be drawn: whether the utilisation of rules has improved the crew's possibilities of coping with the transients and if so, in what way the diagnostic rules were used during the $t$ ansients and finally, any remaining deficiencies concerning the diagnostic rule coverage and structure. The two latter aspects are focussed on for further refinement of the diagnostic rules. The crews' performance during the transients will suggest appropriate adjustments to the sequential order and content of the rules. Clues about discontinuities in the set of rules, largely based on remarks and opinions from the crews, can be used to secure a logical chain of rules covering the entire diagnostic search sequence. The second version is then rewritten to form the final version of the diagnostic rule sets.

\section{Practical use of the final version}

The final version can now be implemented in training schemes, either as part of existing formalised training programmes for nuclear power plant crews or as more isolated courses.

It is obvious that a number of different methods can be used to evaluate and modify the diagnostic rule sets. For example, a very important part is the data collection in its initial phase. This is probably best achieved through semi-structured interviews or observation of operators performing fault-finding activities in their usual environment. A more detailed example of one such method, put into practice, is given in the following section on empiric studies. In addition, see the section on Project 3 performed by the OECD Halden Reactor Project. 


\section{Relation to other Work}

The importance of the area of diagnosis and trouble-shooting is reflected in the breadth of the research which has been carried out over the past twenty or more years. Much of this work has been government-sponsored because of concern about the increasingly large expenditures which are becoming common for the maintenance and repair of modern military systems - expenditures which of ten amount to several multiples of the original purchase price. However, there have also been reports of research which are more directly related to industrial applications - in particular, chemical plants and nuclear power stations. Two such activities are especially relevant in connection with the LIT-4 work being reported here.

Duncan (1980) and Duncan \& Gray (1975) report on the results of some studies of training for fault diagnosis in the chemical process plant area. In essence they were interested in comparing the effects of utilizing different sorts of background knowledge during the training of operators as a potential aid in their subsequent ability to diagnose plant faults. Thus of three groups of trainees, the "theory" and the "rules" groups were given a simplified account of how the plant worked in terms of inputs, outputs, product flows, control loops, etc. In addition the "rules" group exercised in applying diagnostic rules of the type illustrated below. The third group received no prior instruction of either sort.

\section{Diagnostic rules}

(1) Scan the panels to locate the general area of failure.

(2) Check all control loops in the affected area. Are there any anomalous valve positions? 
(3) High level in a ressel and low flow in the associated takeoff line indicates either a pump failure or valve failed "closed". If valves oK (see (2)), then pump failure is the probable diagnosis.

(4) High temperature and pressure in a column head associaled with low level in the reflex drum indicates overhead condenser failure - provided all pumps and valves are working correctly (see (2) and (3)).

(5) If the failure is in the Reactor/Heat-Exchange complex, determine whether it is in the reactor or the hea:-exchange system. A failure in the heat-exchange will produce symptoms in Column $A$ but not in $B$. A failure in the reactor will produce symptoms in both columns.

(6) If the failure is in the feed systen, check whether it is in stream $X$ or $X$. Secause of the nature of the control system, a failure in $Y$ will produce associated symptoms in both $X$ and $Y$ streams. A failure in $X$ will sho symptoms in the $X$ stream only.

It will be noted that the diagnostic rules differ in generality. The first four are rather general. The last two are plantspecific and attempt to assist the operator in dealing with system complexity caused by the presence of feed-forward and feed-back control loops.

Fig.5 indicates the results of a test which followed the training session. These suggest : hat explicit information in the form of instruction prior to pr:atice is effective for NEW fauls not previously seen by the operators during practice. While explanation of how the plant works had some effect, the most encouraging performance was achieved by including information in the form of the diagnostic rules shown above. 


\section{MEAN CORRECT}

DIAGNOSES

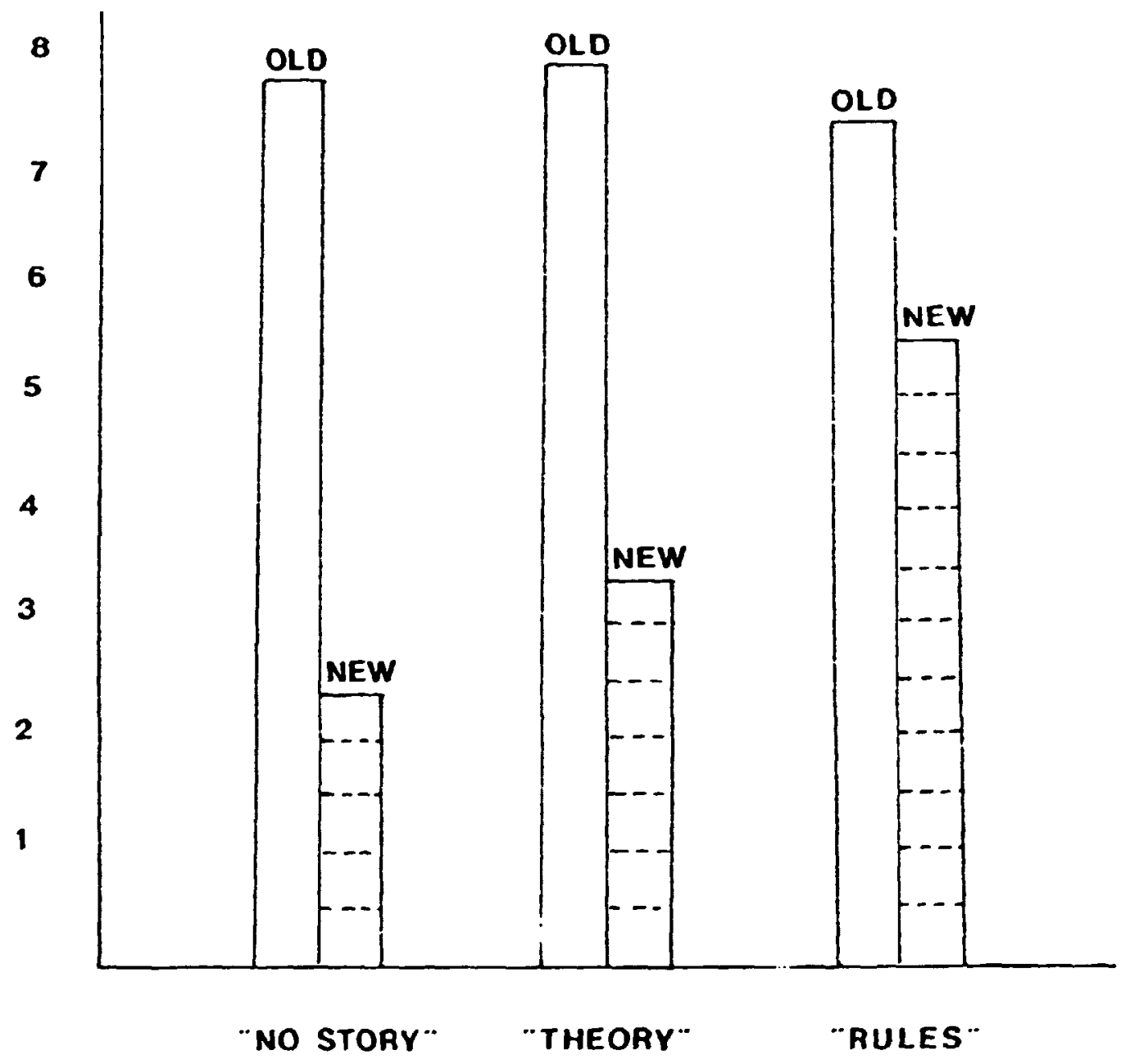

Finure 5. Fault diagnosis following ehree training regimes. 
The other study which will be mentioned is from the extensive research of Rouse and his colleagues - see e.g. Morris and Rouse (1985). This particular work deals with the development and evaluation of a fuzzy rule-based model of human problem solving (Hunt \& Rouse (1982)) which is based on diagnostic strategy studies by Rasmussen (1979). Of special interest here is the fact that the proposed model was designed to search in two different modes - namely a symptomatic search based on the state of the system and a topographic search which relied also on the structure of the system. The model is sketched in Fig. 6.

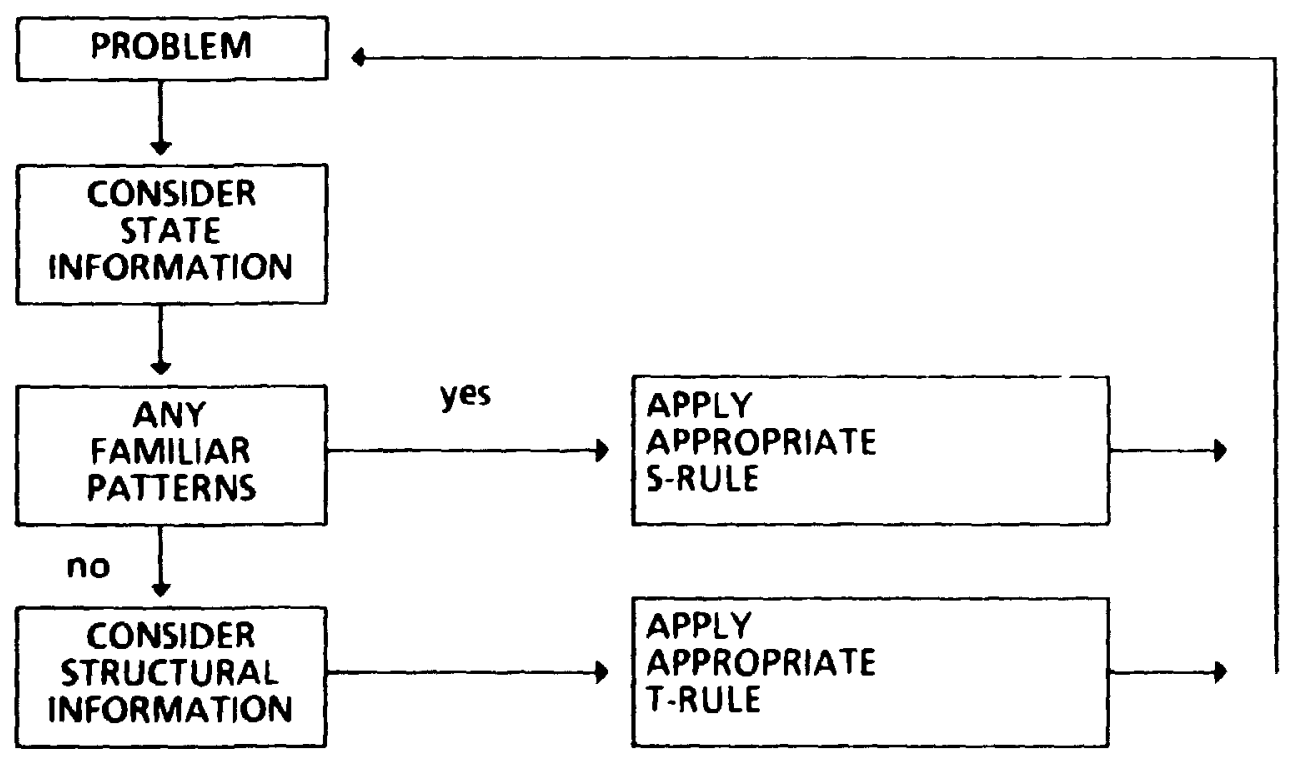

Figure 6

An example of an S-rule, e.g., in connection with automobile diagnosis, might be (in production rule form): 
IF : the engine wili not start - and

the starter motor is turning - and

the battery is strong

THEN : check the gas gauge.

A comparable T-rule could be:

IF : the output of $X$ is bad - and

$X$ depends on $Y$ and $Z$ - and

$Y$ is known to be working

THEN : Check Z.

Rouse points out that S-rules are context-specific since they relate to specific features within a given problem area. On the other hand, T-rules can be considered as context-free since they do not contain such specific references and thus can be used more generally in many situations. S-rules come with experience as sets of pattern recognition rules which map specific plant state to a corresponding hypothesis or an action. On the other hand, people have to be trained to use $T-r u l e s$ AND, most importantly, to know when they should attempt to use them; i.e. to recognize when their available library of S-rules or pattern matches is not sufficient.

Rouse argues for a mixed-fidelity approach to training operators in problem solving - ranging from a zero-fidelity simulator with no context to a moderate-fidelity simulator with the right context for problem-solving (although not necessarily for control and manipulation) and then finally to a high-fidelity unit for final checking. See Rouse (1982). He favors a approach to training which emphasizes general diagnostic skills, based on training in varying problem contexts and thus supporting the use of topologicalrelated rather than symptom-based strategies. 
Training of Diagnostic Rules

\section{Basic Concepts and Purposes in Training}

In a now classic and often quoted definition, Gagne (1965) stated that:

"... learning is a change in human disposition or capability which can be retained and which is not simply ascribable to the process of growth. The change may be, and often is, an increased capability for some type of performance. It may also be an altered disposition of the sort called 'attitude' or 'interest' or 'value'.

The change must have more than momentary permanence; it must be capable of being retained over some period of time."

In this paper the concept of "human disposition" will be referred to as knowledge and attitudes, i.e. denotative and connotative aspects of the phenomenon, for exampie technical system procedure and data. "Capability" indicates the mental and physiolngical functions necessary to obtain the knowledge at a conscious level. The "increased capability for some type of performance" mentioned in the definition could, in everyday language, be expressed as a person becoming better or more thorough or able to cover a broader aspect of the trained performance. The "permanence aspect" of the change will simply be interpreted as the degree to which the learned material is manifest over time.

Applied to the context of diagnostic search in technical systems, this means that the training of operators will focus on increasing their ability to cope with disturbed system states. Sperial onus will then be placed on diagnostic search within technical systems subjected to unfamiliar disturbances to which instructions are not, or are only partially, applicable. 
The training will therefore include the nature, content and application of heuristic diagnostic rules. This is done during training by providing the operators with information about the diagnostic search and rules in order to increase the operators' knowledge in this area and to create a positivz attitude to the utilization of diagnostic search and rules, i.e. a change in the "human dispositions", to quote Gagne. The "capability" aspect. which refers to obtaining this knowledge at a conscious level, is covered in training by applying the diagnostic methods to realistic examples, either in real-1 ife situations or by using a simulator. The purpose is to practise with these examples to such an extent that heuristic methods become a part of the operators' normal search behaviour. i.e. manifest over time.

\section{Understanding and Application of Diagnostic Search in}

Iraining and in Real-Life Situations

Changes in human dispositions and capabilities are in principle of two different types as seen from a qualitative point of view:

- Changes which include the alteration of internal parts or elements within dispositions and capabilities but which will not change the totality of these dispcsitions and capabilities (Type I changes).

- Changes of internal parts or elements in dispositions and capabilities, causing a fundamental change in the totality of the dispositions and capabilities (Type II changes).

These two types of changes correspond roughly to the Piagetian concepts of assinilation and accomodation respectively. The former means that new information is interpreted according to existing standards in the dispositions and yet is too apparent to be ignored. Thus, a reconstruction or change of the dispositions is demanded. To put it crudely, assimilation vis-a-vis training means that the trainee has becone more knowledgable within and according to the structure of the subject concerned. As far as 
accommodation is concerned, it follows that the trainee has altered the entire structure of the subject and consequently rearranged his knowledge according to the altered structure. The two concepts, assiailation and accomodation, are of importance in two fundamental aspects of training:

- As requirement for understanding and profiting from the training content.

It is reasonable to assume that understanding and application of algorithmic diagnostic rules, i.e. in practice, operating instructions, are based on other dispositions and capabilities than understanding and application of heuristic diagnostic rules. The reason for this assumption $l i e s$ in the main difference between the natures of the two types of rules: While the application of algorithmic rules leads to the solution, the use of heuristic rules, more or less explicitly, pinpoints the methods of finding the solution to a disturbance situation. Hence greater capability demands are placed on the operator in the latter case. Obviously, these demands will also occur during training of diagnostic search. If an operator is simply trying to assimilate the heuristic diagnostic search methods by adapting them to his algorithmic method disposition and capability structure, there will be no relevant understanding of, or profit from, the training.

- As requirements during practical application within the technical system

This concerns the impact of training, i.e. the extent to which the operator will apply diagnostic search in general and heuristic diagnostic rules in particular to real-life system disturbances after diagnostic search training has been given. In his every-day work the operator will experience disturbance situations, to which both types of diagnostic rules must be applied. To optimize disturbance solution probability, it is therefore necessary to define and distinguish between the situations in which the respective diagnostic rules should be used. 
The difference in demands on dispositions and capabilities between the two types of rules could probably be explained in terms of differences in required cognitive process levels. These cognitive levels could be organised in hierarchical or taxonomical structures, as in Bloom's cognitive taxonomy for instance. The main headlines in this taxonomy are given below:

\section{- Knowledge}

- Knowledge of specifics

Knowledge of terminology

Knowledge of specific facts

- Knowledge of ways and means of dealing with specifics

Knowledge of conventions

Knowledge of trends and sequences

Knowledge of classifications and categories

Knowledge of criteria

Knowledge of methodology

- Knowledge of the universals and abstractions in a field

Knowledge of principles and generalisations

Knowledge of theories and structures

\section{- Comprehension}

- Translation

- Interpretation

- Extrapolation 


\section{- Analysis}

- Analysis of elements

- Analysis of relationships

- Analysis of organizational principles

\section{- Synthesis}

- Production of unique communication

- Production of a plan or proposed set of operations

- Derivation of a set of abstract relations

\section{- Evaluation}

- Judgement in terms of internal evidence

- Judgement in terms of external criteria

As the procedural aspect of an algorithmic diagnostic rule is normally implied in an instruction or in a sheck-list, for instance, the operator's main concern is the informative aspect. These two aspects correspond to capability and disposition respectively in a diagnostic search sequence. Therefore the operator will therefore mainly use cognitive processes at the levels of knowledge, comprehension and analysis in order to identify the disturbance systems as belonging to a certain disturbance type. In a disturbed situation demanding the application of heuristic diagnostic rules, both aspects have to be dealt with by the operator. Now he must not only identify the disturbance symptoms but also synthesize these symptoms in order to "produce a plan or a proposed set of operations", to use Bloom's terminolology: hence the difference in cognitive levels and consequently different demands on the operator. These different cognitive levels and corresponding demands must be 
considered and used explicitly in the practical training situation in order to increase the probability of understanding and future application of diagnostic search.

\section{Diagnostic Search Training Strategies and Methods}

The term "training method" is often used in a number of different contexts and meanings which can sometimes be confusing. In this paper, it will therefore be defined as follows:

-Training method will refer to the didactic methods used by a teacher or an instructor in direct interaction with trainees, i.e. the various methods used by an instructor in order to present data and information to the trainees. These methods are based on experience and research work concerning human perception and learning processes in practical training situations.

-Training strategy is defined as an overall principle, in accordance with which a specific training content is analysed and structured.

In planning and preparations, the training strategy is used in order to structure the training content according to a chosen overall principle while training methods are tools for the actual presentation of the content to the trainees. A certain training strategy has its corresponding methods or set of such methods. Thus, a training strategy is selected first and appropriate training methods are then determined accordingly. The choice of training strategy is highly dependent on what type of change is required to achieve a certain diagnostic search behaviour. From a practical and simplified point of view, it is a question of whether the existing operator search behaviour demands a Type I change (assimilation) or a Type II change (accomodation) in order to meet the requirements for that certain search behaviour. To answer this question the present operator search behaviour has to be evaluated and compared to the desired search behavlour. 
In the case of assimilation, two sub-types can distinguished: to add information without intending or expecting to change behaviour as opposed to adding information with the intention of altering behaviour within existing disposition structures. Hence the following three main training strategies:

Presentation of facts: This strategy is used when "accumulative learning" is intended. The purpose is to add new information and data to enable the operator to anchor more solidly his present search behaviour within his broader knowledge. Change of search sehaviour is neither implied nor expected.

Adaptive training strategy: New information and date are presented with the intention of changing certain parts of the disposition structure without altering its totality. This is done by assimilating facts in accordance with present structure.

Confrontative trainirg strategy: This strategy derives its name from the "confrontation" of new information to existing disposition structure. The new information is deliberately presented to the trainees in such a way that their existing disposition structure cannot assimiltate the information. The presentation will also ensure that the information cannot be ignored. This is done in order to achieve accommodation, i.e. a complete change of the disposition structure.

As mentioned previously, the actual implementation of these strategies is, done by choosing training methods in accordance with the nature of the training strategy. It goes without saying that it is difficult, if not impossible, to outline these training methods without knowing the specific training situation and its strategies.

Training methods consist mainly of activities which are introduced by the instructor in a predetermined order. Examples of such activities are lectures, group discussions, group work, laboratory experiments, scenarios, individual work, programmed training, field exercises, demonstrations and study visits. 


\section{Training Initative and Motivation}

The key factor influencing motivation for behaviour change has previously been said to be discovery of discrepencies between present and desired hehaviour. Training could then be a means of achieving behaviour change. But on whose initiative? The question is justified for many reasons but only the strict training aspect will be discussed here. There are a number of representatives from different groups who can point out training needs: the crew members themselves, labour unions, training organisation at the utility, plant management, central training organisations, government nuclear power authorities, research projects etc. As training results are highly dependent on degree of both general motivation for training and specific motivation for diagnostic rules, it is worth examining the motivational aspect a little closer.

Some aspects contribute to make the issues of training initiative and motivation slightly sensitive.

- The subject in itself.

The nature of the subject diagnostic search/rules is somewhat different from those normally covered in nuclear power station training. It includes issues which have bearing on more personal individual matters than technical subjects.

The mere fact that it comprises fewer "truths valid for all kinds of situations" could give it a reputation of being of little value in practical situations.

- Priority.

The time available for control room crew training is fairly limited. The number of technical refinements and changes at the plant over a period of time is normally of such magnitude that instructors in training organisations find it necessary to allocate most of the time available to these changes. As trairing 
of diagnostic rules has not been carried out before, it will be accorded a low priority under these cirrumstances.

- other aspects.

Perhaps of a more subtle nature but still valid is the point that diagnostic rule training may be regarded as a sign of imperfection in the crew's professionalism. This is especially relevant when a person from another field of work and/or with a different professional background points out the need for diagnostic rule training.

An even more subtle aspect is the image of complete safety in the running of nuclear power stations, maintained for the public's benefit by the utilities and goverment authorities. In Scandinavia, for example, this issue is of great importance due to its political sensitivity. The introduction of diagnostic rule training, with its less "stringent" nature, could be interpreted as resorting to methods which contradict repeated assurances of safety.

It goes without saying that the best basis for training of diagnostic rules from a motivational point of $v i e w$ is a request for such training by the crew themselves. The attitudes behind such request are then based or the fact that the crews want to learn the methods involved because it would have an instrumental function in dealing with disturbances. If dictated by others, defensive attitudes in the crew members could easily result. This $k$ ind of attitude is dominated by its affective component which is much more difficult to deal with than a knowledge- related attitude. Once evoked, it is fed by more or less logical reasoning derived, for instance, from opinions mentioned above about the subject per se or other aspects.

As a result, therefore, it is of great importance to ensure that the crew's decision to participate in diagnostic rule training is built on knowledge-related attitudes. This requires both avoidance of conditions which create the formation of other attitude types and an appeal to fact-related circumstances experienced by the 
crews during fault $f$ inding activities. Complementary knowledge and methods should be discussed rather than a crew's errors of judgement. The latter will be brought up anyway during the training but then often by the crews themselves in order to exemplify situations in which diagnostic guidance is of positive value. Initial and preparatory contacts should be made either directly with the crews or via representatives who are "incluied in value-expressive attitudes". If possible the contacts should be made personally and in "face-to-face" situations followed up by extensive written information about the training to come. Channels of communication between the crews and training organisers should be opened and their use encouraged throughout the period before the start of the training. Thus, the leading principle during the preparations for the diagnostic rule training is to provide as much information as possible aiming for knowledge-related attitudes and to reinforce the eognitive component in positive object-instrumental attitudes.

\section{Training definition and analysis}

The purposes of this definition and analysis are related to decisions necessarily made during other preparatory analyses and activities concerning the training of diagnostic rules:

- Goal analysis

- Content analysis

- Group composition

- Training methods

Even though training of diagnostic rules could be held at a very general level, i.e. applicable to a variety of technical systems, the use of examples during the training requires a common frame of reference for the trainees. This indicates a preference for groups which are homogeneous in a number of aspects, for example with 
reference to work content, educational background, previous experience and so forth. The definition of the training target group will therefore be based on personal factors concerning the potential participants in the training. In a nuclear power station, it is advantageous to split up the staff in accordance with work content rather than attachment to, for example, reactor units.

The subsequent goal analysis is in some cases based on discrepancies between present and desired behaviour repertoires: an analysis of requirements in order to change the present repertoire is therefore necessary. If it is vital that the present repertoire is defined in very precise terms, the analysis could be quite extensive and therefore time consuming. Normally a rough idea is sufficient because of the stronger emphasis on the objectives of the training, i.e. achievement of the desired behaviour repertoire. In the practical training situation, it is in any case very difficult to allow for individual differences in behaviour repertoires. A solution to this difficulty couid be to use some kind of estimated "average level" when comparing present and desired behaviour repertoires.

\section{Setting up training goals}

In order to determine training goals, a general overall goal for the diagnostic rule training is first formulated, e.g.:

Training of control room staff in the nature and application of diagnostic search methods in order to facilitate constructive and adequate search behavior re-pertoires during disturbances of various types.

This sentence provides material for the breakdown process starting with main goal categories and ending with basic elements. In the second level subcategorical goals are stated in terms of knowledge, skills and attitudes preferred in the different types of disturbances. At the basic element level these preferences are 
broken down into further quantitative and qualitative detail which is later used as a base for the instructor's lecture plans. As the goals are directly dependent on preconditions derived from previous training analyses concerning a certain training target group. only examples of training goal descriptions can be given here.

$\begin{array}{lllll}\text { Main } & \text { Purpose of } & \text { Diagnostic Application } & \text { Weaknesses } \\ \text { categories } & \text { diagnostic search } & \text { of diagnostic in human } \\ \text { search } & \text { sequences } & \text { rules } & \text { fault } \\ \text { methods } & & & \text { finding } \\ & & & \text { behaviour }\end{array}$

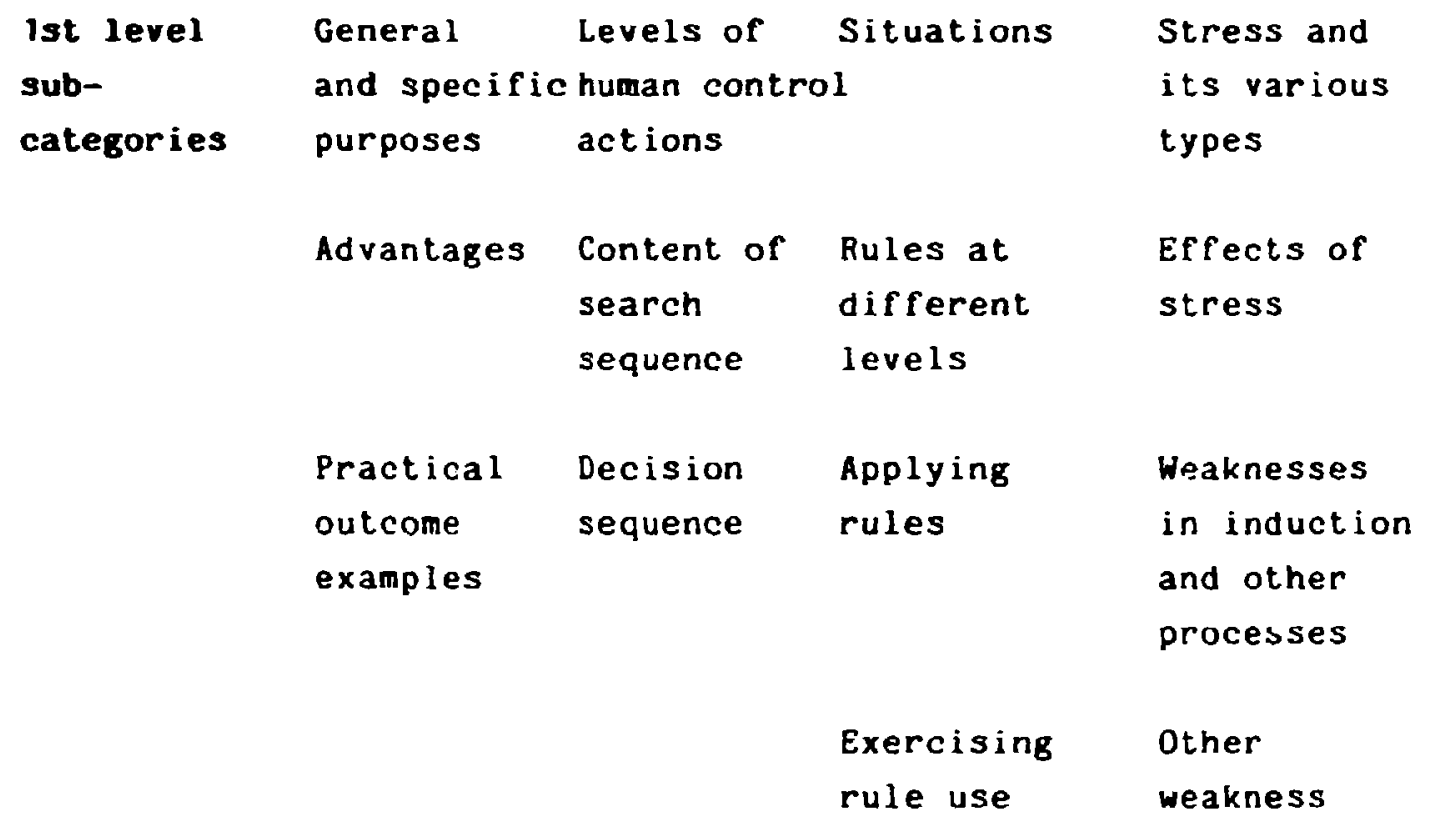

At the remaining two levels, the stated subgoals are further specified in the respective dimensions of knowledge, skills and attitudes. A practical example of this is found in a later section of this report. 


\section{Training content and methods}

Based on the detailed goal specifications obtained at the basic goal element level, a training syllabus is drafted for an overview of how the training will be carried out in practice. This draft shows the different training items in the chronological order in which they will be considered during the training. The criteria applied in arranging training items in chronological order are based on logical reasoning and past experience arising from the impact of this kind of training. It is, in other words, fairly difficult to state an exact rule for the order of training items in general. In practical circumstances a preliminary version of the training is made and tested using participants from roughly the same target group as is intended for the final training. Results from this test run are then used as a basis for alteration of the training content.

The training content draft is analysed item for item to determine each item's applicability learning aspects ("internal factors") and the method of communication to training participants ("external factors").

\section{Internal Pactors}

- Degree of abstraction required for understanding and coping with the training

- Type of mental processes involved in learning of training items

- Taxonomicial level of the different training items

\section{External factors}

- Learning level with regard to participant learning exercises in practical terms

- Type of general training method appropriate for exercising the respective training it tems

- Type of teaching method required 
- Type of behavioural change required in order to comply with the training item behavioural implications
- Preserving proper motivation: material/exercises, generalisation and reinforcement

- Audio-visual aids required for the respective training i tems

When considering these factors from a practical point of view the analysis boils down to the following reasoning:

Desired behaviour repertoire in diagrostic search

- Actual behaviour repertoire during diagnostic search

$=$ Required change in order to achieve the desired repertoire

The words "required change" constitute all kinds of alterations including literary, behaviour changes, adding new behaviour or extinguishing present behaviour elements. In order to achieve this required change in an efficient and profound way, the training methods must correspond to the requirements of the respective training items. In the case of diagnostic rule training, the impact of the training will be superficial or non-existant if the correct training methods are not used. 


\section{Eopirical Studies}

The main purpose of the LIT-4 project was twofold: to develop and test operator training methods concerning normal and disturbed conditions and to develop and test aethods for systematic observation, analysis and interpretation of operator performance during training in a simulator. From a practical and a methodological point of view, the latter bec3me a precondition for the former, i.e. in order to evaluate the developed training methods it was necessary to construct and use some kind of observation method.

The general purpose of the empirical investigation was to evaluate different aspects of diagnostic search during disturbed system states. That is:

a. To evaluate the utilization of diagnostic rules in connection with the diagnosis of disturbed system states.

b. To evaluate the developed observation method during operator simulator training.

c. To evaluate the content and realization of the diagnostic rule training course within the project.

Later these aspents were broken down further into questions. expressed in operational terms, in order to facilitate assessment.

The investigation was split up into the following phases:
a. Preparations which included administrative contacts,
diagnostic rule construction, preparations for training courses etc.
b. Training courses for operators and instructors
c. Data collecting 
d. Analysis and reporting of results

The following groups participated:

- Control room staff from two PWR units at the nuclear power station at Ringhals in Sweden. The staff consisted of 59 persons allocated to 14 crews at number 3 and 4 units. These units are virtually identical and are situated within 100 metres of each other. Each crew taking part in the investigation consisted of a shift supervisor. two reactor operators and normally one turbine operator. Seven crews work in shifts at each unit.

- Instructors at the nuclear power station crew training centre, AKU, at Studsvik in Sweden. These instruztors are involved in the annual retraining of all pun crews in Sweden which takes one week. All in all, five PHR instructors participated in the data collecting as observers.

- LIT-4 project staff at Riso National Laboratory in Denmark. The field work and training courses were carried out by a Swedish nember of the staff.

The diagnostic rule constructicn was undertaken mainly at hinghals in cooperation with three of the fourteen crews. The remaining eleven crews took part in the data collecting during their annual retraining at $A K U$.

Meetings with crew members and instructors who participated in the ingestigation are scheculed for february 1986. The purpose of these meetings is to give a result reed-back and to discuss the results with the operators and the instructors.

In the table below which shows the principal investigation variable set-up, the investigative aethods will be described in the order in which they appear: 


\author{
Independent \\ variable \\ Diagnostic \\ rule training
}

(requires

appropriate

and efficient

training stra-

tegies, methods

and content)

Sub-purpose $c$.

\section{Internediate}

variable

Utilization of

diagnostic rules

during simulator

sessions

\section{(requires}

appropriate

observation

methods etc.)
Dependent

variable

Qualitative

results of diag-

nostic rule

utilization

(requires

effective

diagnost ic

rules)

Concerning sub-purpose a.. the task was to find out whether instruction regarding a set of diagnostic rules improved the operators' treatment of simulated system disturbances. Two different methods were used in order to answer this question:

- Comparison between observed and registered treatment of disturbances of two groups, where one group had participated in diagnostic rule training.

- Collection of opinions from the group whose members had participated in diagnostic rule training concerning the support recsived and usefulness of these rules.

The eleven crews particifating in the data collecting were allocated to the experimental and the control groups by stratified sampling from each reactor unit in order to achieve two similar and comparable groups. Background and other factors were checked for the respective groups and found to be acceptably similar. The six crews in the experimental group and the remaining five in the control group participated in the data collecting as follows: 


\section{Experimental Control group group}

Project and data collecting information received

Diagnostic rule training participation

Observed during simulated

disturbance treatment

Yes

Disturbance treatment results calculated
Yes

Yes

No

Yes

No

Yes

A criterion variable, containirg four criteria, was set up in order to define the dependent variable in operational terms. These criteria were: elapsed time from the on-set of disturbance symptom to the operators' possible recognition of these symptoms; cause identification; understanding of cause consequences; and execution of disturbance counter-actions.

Collection of crew-member opinions was made by using a number of questionnaires, containing a variety of disturbance cause and treatment questions formulated according to the Likert attitude scale technique. In principle, these questions were based on the diagnostic search sequence and the afore-mentioned criteria.

Concerning sub-purpose b., the main task was to construct an observation form to be used initially for the LIT-4 project data collection and later by instructors during future simulator training. The following considerations were important:

- The observation form should be based on the diagnostic search sequence. 
- It should contain an explicit time scale in order to enable chronological recording of operator actions during the simulator session.

- It should provide opportunities to record simple qualitative operator action evaluations within each phase of the diagnostic search sequence.

- It should, in general, be easy to administer and fill in.

- It should be possible to make written remarks and explanations in a logical order and in a convenient space on the form.

- It should provide data about various technical aspects of the simulator session, such as crew identification, instructor, type of disturbance and time aspects of the observations.

- The form should allow for the utilization of easily-recalled symbols and filling-in techniques for the recording of all possible operator action types.

Finally, sub-purpose c. required the construction of an appropriate diagnostic rule training course. As the duration of the diagnostic rule course was very short ( 5 hours), compromises concerning training strategy had to be made. One of the unfortunate compromises was that no "accommodation-type" learning could realistically be accomplished and therefore was not targetted during the training. The figure below shows the course content according to the result of the goal and the content analysis methods mentioned previously: 


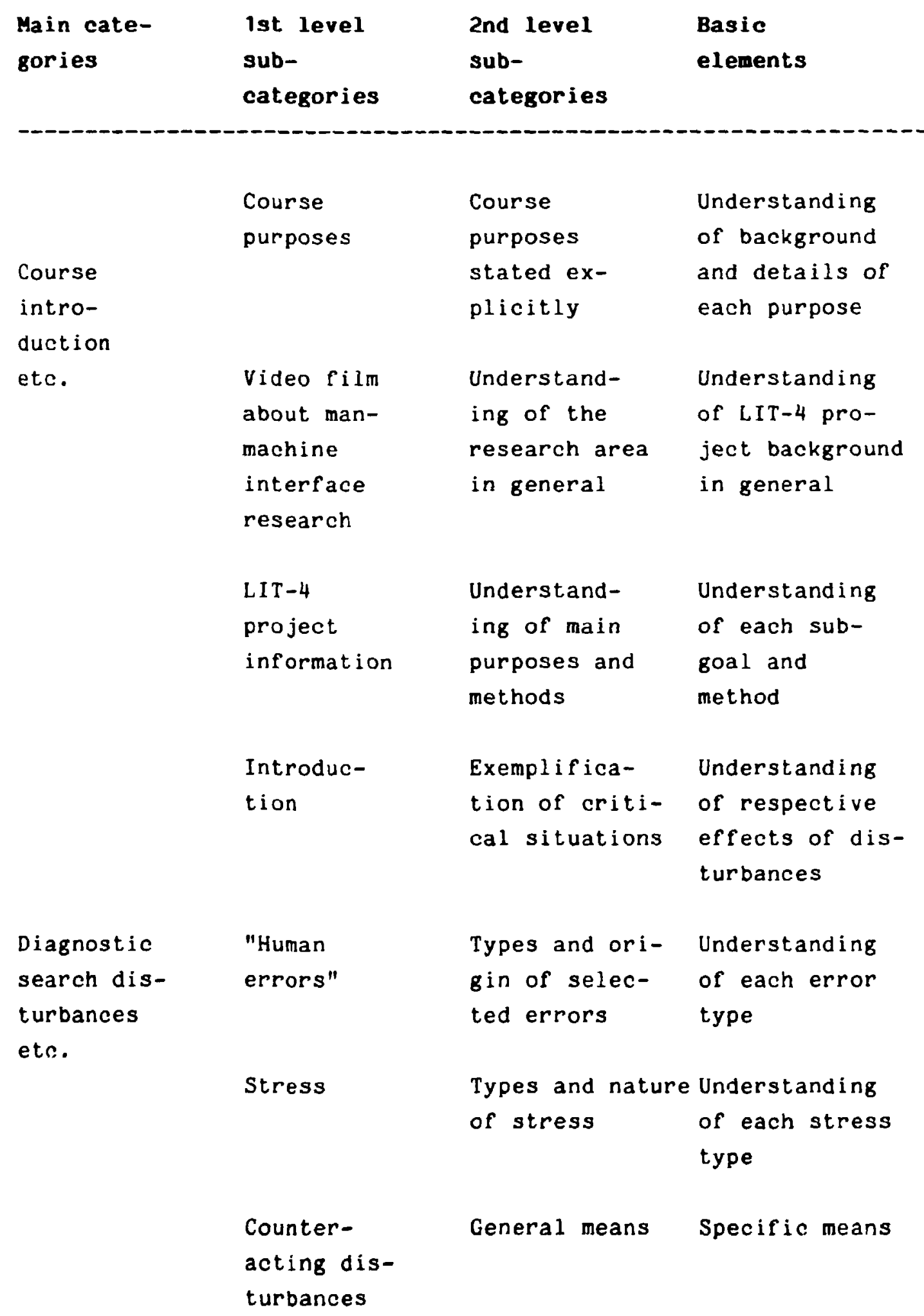




\begin{tabular}{|c|c|c|c|}
\hline $\begin{array}{l}\text { Main cate- } \\
\text { gories }\end{array}$ & $\begin{array}{l}\text { Ist level } \\
\text { sub- } \\
\text { categories }\end{array}$ & $\begin{array}{l}\text { 2nd level } \\
\text { sub- } \\
\text { categories }\end{array}$ & $\begin{array}{l}\text { Basic } \\
\text { elements }\end{array}$ \\
\hline & $\begin{array}{l}\text { Introduc- } \\
\text { tion }\end{array}$ & $\begin{array}{l}\text { Clarification } \\
\text { of concepts } \\
\text { and area to be } \\
\text { dealt with } \\
\text { during the } \\
\text { course }\end{array}$ & $\begin{array}{l}\text { Motivational } \\
\text { factors con- } \\
\text { cerning each } \\
\text { concept and } \\
\text { sub-area in } \\
\text { which diagnos- } \\
\text { tic search can } \\
\text { be applied }\end{array}$ \\
\hline \multirow{6}{*}{$\begin{array}{l}\text { Decision- } \\
\text { makinz and } \\
\text { diagnostic } \\
\text { search }\end{array}$} & $\begin{array}{l}\text { Decision- } \\
\text { making }\end{array}$ & $\begin{array}{l}\text { Decision- } \\
\text { making se- } \\
\text { quence }\end{array}$ & $\begin{array}{l}\text { Understanding } \\
\text { of each step }\end{array}$ \\
\hline & $\begin{array}{l}\text { Diagnostic } \\
\text { search }\end{array}$ & $\begin{array}{l}\text { Diagnostic } \\
\text { search sequence }\end{array}$ & $\begin{array}{l}\text { Understanding } \\
\text { of each step }\end{array}$ \\
\hline & $\begin{array}{l}\text { Behaviour } \\
\text { types }\end{array}$ & $\begin{array}{l}\text { Behaviour typo- } \\
\text { logy background }\end{array}$ & $\begin{array}{l}\text { Respective be- } \\
\text { haviour type }\end{array}$ \\
\hline & Synthesis & $\begin{array}{l}\text { Synthesis back- } \\
\text { ground and prin- } \\
\text { ciples }\end{array}$ & $\begin{array}{l}\text { Understanding } \\
\text { of each part } \\
\text { and overall } \\
\text { picture }\end{array}$ \\
\hline & $\begin{array}{l}\text { Introduc- } \\
\text { tion }\end{array}$ & $\begin{array}{l}\text { Clarificalion of } \\
\text { concept area }\end{array}$ & $\begin{array}{l}\text { Understanding } \\
\text { of each concept }\end{array}$ \\
\hline & $\begin{array}{l}\text { System of } \\
\text { diagnostic } \\
\text { rules }\end{array}$ & Principles & $\begin{array}{l}\text { Understanding } \\
\text { each principle }\end{array}$ \\
\hline $\begin{array}{l}\text { Diagnostic } \\
\text { rules }\end{array}$ & $\begin{array}{l}\text { Diagnostic } \\
\text { rules in } \\
\text { practice }\end{array}$ & $\begin{array}{l}\text { General situa- } \\
\text { tions }\end{array}$ & $\begin{array}{l}\text { Specific situa- } \\
\text { tions }\end{array}$ \\
\hline
\end{tabular}




$\begin{array}{lll}\begin{array}{l}\text { Diagnostic } \\ \text { rules }\end{array} & \begin{array}{l}\text { Diagnostic } \\ \text { phases }\end{array} & \begin{array}{l}\text { Diagnostic } \\ \text { units and } \\ \text { rules }\end{array} \\ & & \\ \text { Practical } & \text { Identification Application of } \\ \text { exercises } & \text { of diagnostic } & \text { units and } \\ & \text { phases } & \text { rules }\end{array}$

The training methods were dictatec by the course content.

The construction of the diagnostic rules to be used later in the diagnostic rule training course was as far as possible carried out according to the principles described earlier. Unfortunately, one special circumstance made it necessary to make an important alteration of the original construction plans. Since specific diagnostic rules, especially algorithmic rules, are very similar to operation instructions, the utility and $A K U$ requested that only rules at general and operational levels should be implemented in the diagnostic rule training due to the risk of confusion with existing operating instructions. This request was ganted of course, and the work was altered accordingly.

During the initial stages of the rule construction, ocher sources than nuclear power station staff were used: for example, aviation pilots. Thus, the data collection for the first version of the diagnostic rule set was carried out in the following prinaipal way :

General Rules

Interviews with two crews

at the research reactor

DR3 at Risø National

Laboratories in Denmark
Operational Rules

Interviews with three crews at the no. 4 PWR unit at the Ringhalis power station in Sweden. 
Interviews and simulator

studies at two aviation

training centres in Denmark

(Jetair and Sterling Airways)

in which 11 commercial pilots

participated.

Three criteria were applied to the choice of incidents quoted during the interviews:

- The interviewed crew member should have been personally and actively involved in the disturbance, i.e. he should not have acted merely as a spectator or have heard about the incident from others.

- The interviewed cirew member should have experienced uncertainty regarding the cause of or counteracting procedure(s) for the disturbance.

- The nature of the disturbance quoted should be fairly complicated; i.e., preferably involving the entire diagnostic search sequence.

The crew members, whether nuclear power station staff or pilots, were interviewed individually for 1-3 hours. In the interview, three main items were covered: noture of disturbance, methods of solving the problem and other phenomena (technical and "mental") which they experienced as disturbing or as making the problemsolving process difficult. All interviews :ere carried out with the same LIT-4 project staff memier as interviewer.

The interviewer's notes from these interviews were analysed, and about 60 short sentences were extracted in more or less diagnostic form. These were further analysed and finally reduced to 28 reformulated diagnostic rules. 
Close examination of the obtained rules showed that headlines which corresponded roughly to the diagnostic search sequence could be used. The headlines were re-formulated in everyday language:

1. Determine and delimit the affected area

2. Collect and verify information

3. Put information together to form a picture of what has happened

4. Suggest cause(s) of disturbance

5. Determine and locate the disturbance

6. Counteract the disturbance.

The diagnostic rules were now placed under each headline and analysed according the following criteria:

Verbal form

- One single sentence

- Number of words preferably not exceeding 15 and certainly not more than 25 words

- Put in a positive way, i.e. no negations

- Everyday language

- Only one suggested action in each rule

- No ambiguous concepts

Methodo-

- Covering an entire diagnostic search

logical sequence

- Dduction of specific rules possible

- Possible to explain as part of a diagnostic search strategy 
others

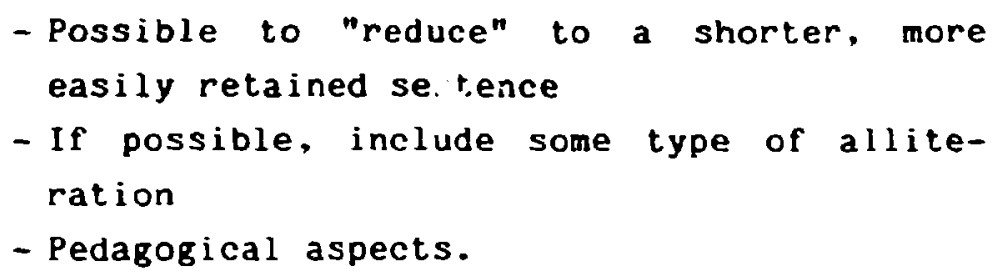

The first version was drafted and discussed by the previously consulted number 4 unit crews at Ringhals, and this resulted in a reduction of number of rules to 18. This second version of the diagnostic rule set was further discussed with the control room crews and, from a pedagogical point of view, with instructors at AKU. The main decision resulting from these discussions was to exclude six rules concerning more technical aspects of fault symptoms which brought the number of rules down to 17. Thus the following rules constitute the diagnostic rule set used later in the training:

1. Determine and delinit the affected area.

1.1. Clarify which system is affected (by alarm or other means of disturbance discovery).

1.2. Put up rough limits to the affected area about which information should be gathered.

2. Collect and verify information.

2.1. Check and determine the most important variables in the affected area.

2.2. Check and determine the interconnection between these variables.

2.3. Check the correctness of the values of these variables.

3. Put information together to form a picture of what has happened. 
3.1. Create a mental picture of the affected system(s).

3.2. Go through the course of events using this mental picture.

3.3. Consider all collected information (including information of a kind not expected (unanticipated)).

4. Suggest cause( $s$ ) of disturbance.

4.1. Suggest cause( $s$ ) of disturbance based on the processed information.

4.2. Scrutinize the respective suggestions in a very critical way.

5. Determine and locate the disturbance.

5.1. Determine the two points before and after which undisturbed conditions prevail and then go systematically through the syst 3 between these points, either "upstream" or "down-stream", in order to find the cause of disturbance.

5.2. Be especially observant about valve positions and pump indications in the affected area.

6. Counteract the disturbance.

The reason for the absence of rules concerning counteractions is that control room instructions cover this part of the diagnostic rule sequence very extensively and thoroughly. The training management at Ringhals and instructors at AKU therefore suggested that no diagnostic rules regarding this part should be included in the training due to the afore-mentioned risk of interference with these instructions and well established routine crew procedures. 


\section{Data Collection Procedure}

The data collection was carried out at AKU in Studsvik from January to April 1985 during the normal annual retraining of PWR crews from Ringhals. Each crew stayed at AKU for one week during which, all-in-all, five types of transients were run on the fullscale PWR simulator. The PWR instructors functioned as observers for the data collection which involved three of the five transients. The first observed transient concerned a high pressure pre- heater drain valve which the crews would be likely to forget when resuming full power output after a temporary power reduction. This would result in a destroyed valve and a false control room panel indication showing the valve to be closed. In reality this valve was fully open with subsequent pressure and temperature problems.

In the second observation transient, a turbine blade broke and penetrated one of the condensors causing substantial damage and leakage in this condensor. Due to the influx of salt water, increased conductivity would trigger of conductivity alarms which would lead the crews to certain standard procedures.

The last observation transient was based on the development of symptoms which indicated a well-known disturbance (steam generator tube rupture) but the cause behind these symptoms was of a completely different origin. The counteractions to a tube rupture would not improve the disturbed situation but only divert the crew members' attention. The real reason was a spuriously opened pressurizer spray valve which caused symptoms similar to a tube rupture.

In each transient, criteria for certain critical events were defined and used as templates for observation of the crew members' performance in the simulator.

When the crews arrived at AKU, they were reminded of the data collection and its procedure by way of written information handed out by an instructor. This procedure consisted of the following events: 
- Information about the data collection.

- Filling-in of crew member background data form.

- Observation of crew performance during the three transients mentioned above. These transients were run in the simulator on Tuesdays, Thursdays and Fridays respectively.

- Crew interviews directly after each transient.

- Completion of a form concerning transient response by crew members.

- Completion of a form concerning transient response by the involved instructor.

In order to collect data and opinions about the transients, use of diagnostic rules and other aspects of crew background, attitudes and performance, a set of forms (with accompanying instructions) was constructed to gather both facts and opinions. It was important to bear in mind that there were time constraints with regard to completion of the forms. In addition they had to be similar in form and easy to explain and administrate. Thirdly, there was the need to be able to quantify the data in order to prepare e.g., frequency tables for statistical estimates and the Iike.

Briefly, the set of forms consisted of the following:

Form 1 for direct observation by the instructor of crew performance on the simulator. This included time scale, steps in the diagnostic search process, etc.

Form 2 for obtaining crew opinions with regard to the diagnostic rules - before their actual application. 
Form 3 for obtaining crew opinions about working methods. coordination, handling of disturbances during the simulated transients, comparison between simulator and the actual plant, etc.

Form 4 for obtaining crew opinions about difficulties in the simulated transients, methods for dealing with them. which parts of the diagnosis were particularly difficult. usefulness of the diagnostic rules, etc.

Form 5 for obtaining crew opinions about the completion of the transient from a technical point of view, how the crew functioned together during the transient, diagnostics methods, whether training in diagnostic rules had changed the way of working, etc.

Form 6 for obtaining crew opinions about the content of the diagnostic rule course, how well the course corresponded to expectations, to what extent diagnostic rules are needed in control room work and their possible use in the future, etc.

As prolonged periods of observation are exhausting to the instructors and could also disturb the retraining as such, special parts of the transients were picked out for observation. These parts were exactly 20 minutes long each.

The whole data collection process had been explained during a three-day instructors: course, which included information about interview techniques and observation methods etc. The instructors observed one crew during their retraining week, and the results were analysed during a follow-up instructors' course of one day. After each retraining/data collection week, the results were sent to the project staff to ce analysed.

\section{Analysis Methods}

The data analysis was done by using two basic methods: 
- Chi-square tests concerning possibie effeets of diagnostic rule utilization. The data for this analysis were provided by using Likert scale type questions in the above-mentioned foras.

- Qualitative aralysis of the data provided by form 1. This analysis was based on the identification of patterns of crew actions during their treatment of the simulated disturbances. When ine number of actions permitted statistical testing. Chisquare tests were carried out as supplements to the paitern identification.

\section{RESUL.TS}

To sum up:

- The training and data collection involyed 59 operators from 14 crews at the Swedish nuclear power station at Ringhals. Six of the crews participated in a diagnostic ruie course, lasting five hours. The course consisted basicaily of the explanation and acplication of twel de diagnostic rules.

- Data was subsequently collected during a total of 33 simulator runs using the three transients. Each lasted about 20 minutes.

- Two methods of data collection were used; observation of crew performance and gathering of crew and instructor opinions about various aspects of crew performance.

It was obvious from the results, both from written and from oral crew member comments, that some kind of supplementary operator support is highly desirable in disturbed system state situations to which no instructions are applicable. As no such operator support has been included in the crew members' previous training, the basic attitude of the participating experimental group members was very positive towards the diagnostic rule course. In principle, they considered the diagnostic rule methods to be a 
valuable and important support in disturbed system conditiuns. The practical circumstances of the LIT-4 project diagnostic rule course did not. however, allow for more than five hours' diagnostic search training. This is, of course, completely inadequate when trying to impart search methods based or. heuristics. the nature of which are totally different from algorithmic methods. Therefore. it is hardly surprising that the subsequent data collection on the simulator did not show any substantial differences between the experimental and control groups. Thus, the main result should be regarded as the recording of positive attitudes by the crew members towards heuristic diagnostic rules. It is encouraging that 58 per cent of the crew members had the rules in mind, despite the short duration of the diagnostic search training. Equally encouraging is the fact that 95 per cent of these crew members found the diagnostic rules to be helpful during the transient treatments. This could be regarded as a hint of the potential advantages of a diagnostic rule course of longer duration.

The observation method based on form 1 could be used routinely in simulator training provided that appropriate and sufficient training of instructors has been given. Form 1 could of course be altered in different ways to suit various practical circumstances, but the principle of diagnostic phases should be kept intact. As these phases are based on the normative way of approaching disturbed system states, data concerning the phases will provide a logical and structured analysis of crew performance for the subsequent transient de-briefings which, in turn, can eventually lead to adjustments/revisions in the diagnostic training.

The content and presentation of the diagnostic rule course have shown that the nature and application of diagnoctic rules can easily be understood by control room crew members. 


\subsection{STUDY OF HUMAN ERRORS DURING SIMULATOR TRAINING}

\section{Introduct ion}

At the Technical Research Centre of Finland we have been studying problems of process operation for some years. This research has, for the most part, been coordinated through the Nordin projects on design and operation of complex energy systems. For organizing and directing our own work, we have found it necessary to try to define a comprehensive research plan or programme which we call "Enhancing the Mastery of Work in Process Operation". In this approach, human reliability has been considered as one criteria of well mastered work, but it has not been evaluated in probabilistic terms.

For conscious developing of process operation, it is necessary to understand how the present situation has evolved in a historical perspective. Thus, we have made an effort to outline the historical phases of power production. This we have made, firstly, from the point of view of the development of the technical means of mastering different energy conversion processes (which themselves have become longer and more complicated). Secondly, we have defined the corresponding activities of process operation work. Thirdly, we have found it necessary to analyse also the phases in development of theories that have been formulated in order to consciously connect the development of the proess and its man-machine interface. As a result of these analyses we are defining the area of problems in the automation concept of the process operation activities and the corresponding theories that would most probably represent the next deveiopmental phase.

The developmental analysis is concretized through an empirical analysis of the power plant operation. We have started this with a preanalysis based on selected empirical studies reported in the literature. Particularly we have tried to find works in which the problems of process operation have been formulated as certain 
paradoxes or internally conflicting tendencies in the demands of this work.

\section{The Problem of Learning in Work}

One of the paradoxes in operating highly automated processes is the problem of learning in work. How is it possible to learn and maintain the necessary operating qualifactions if practically all possibilities of active control are reduced through highly reliable automation. One apparent help in this situation is the use of training simulators to create the lacking experience, particularly, in very rare and complicated situations. But as e.g. Brehmer (1980) and recently Wagenaar and Keren (1985) have pointed out, learning of complex relations does not take place spontaneously on the basis of experiences. Instead, a concept is needed of what should be learned.

This is not unknown to instructors in complex industrial systems. There is a considerable amount of theory that is included in the training of operators. Yet, and this is clearly shown, e.g. in experiments by Broadbent and Aston (1978), verbal knowledge of the process does not seem to enhance the operating skill. Hence, there seems to be a fundamental problem of mediating between the world of knowing and doing. Knowledge is demanded in the form of activity systems, not as "knowing".

The contradiction in the learning process is reflected in the mastery of the central demand of this work, i.e. in diagnostic judgement. An empirical way of learning from experience would produce a judgement activity of the same spirit. From its essence it is choosing among given, even though sometimes very complicated, action alternatives. The concept of the object is a summary of experiences of the object. Activity based on this is sufficient for mastering the existing or identified demands and assures a reasonable level of reliability. 
It is incomplete in the sense that it does not have potential for development. This is due to the fact that it does not include the means to construct action alternatives. These means spring from the motives and grounds of the actions. A judgement of this kind could be called theoretical in contrast to the empirical judgement. This characterization would indicate that a particular situation is constructed as a concrete form of the general dynamical laws that explain it. To achieve this, common exactly formulated concepts are needed. Instead of choosing, the operator is in this case mentally constructing the solution. On this basis he might be able to define the means he needs and decide whether or not there are ready methods to act in the situction.

It is important to note that theoretical judgement would mean a general improvement in the mastery of the work demands. We think that it does not only apply in some extreme cases in work, even though it might become crucial in such. Thus, we are not talking about knowledge-based behaviour in the sense of the level of actual action control. Instead we mean that this kind of theoretical mastery is a general trait of activity and characterizes its internal structure in every situation independent of the actual level of action control.

\section{Some Results of Operation Problems on Simulated Transients}

As a first step in seeking evidence of the existence of the different levels of mastering judgement demands, we performed a series of simulator experiments. In them we collected data of operator errors and tested the suitability of a certain error collection method for simulator training proposed as a part of Nordic cooperation (Norros and Sammatti, in press).

The starting point in trying to derive specific hypotheses for this study is the fact that the general level of the operators' process knowledge and operating skill is high. Two things shcw this. The qualifications of the operators are regularly tested by 
the licensing authorities. Furthermore, from an international comparison, the availability in both Loviisa plants is very high.

On the above basis it would be reasonable to think that possible operator errors would occur in carrying out well mastered action programmes, i.e. such errors that have been called slips (Norman 1985). From mich evidence of the problenis in operating complex systems it is, however, reasonable to assume that, in a disturbed situation, operators also commit errors of intention or mistakes as Norman calls them.

1. Our first hypothesis is that failures of orientation or in general knowledge are central in disturbance situations. Leaning particularly on the results of Broadbent and Aston (1978), the operators' knowledge is demanded in the form of activity systems, not knowledge as such. Thus there would appear also deficiencies in the high level action planning and integration of actions.

2. Action planning must inevitably be collectively performed which requires common explicit conceptual means and methods to act as a group. These demands might not be adequately mastered and this would become observable in performance deficiencies.

3. We suppose, furthermore, that these tendencies would become stronger the higher the complexity of the task.

4. If these problems are tied to the critical demands of this work, they should differentiate between crews of different levels of mastery.

In the study, operators performed two different simulated disturioances (experiment I and II) and defined afterwards, during discussions with the instructor, the nature of the possible failures in their performance. A failure was thus a deviation from an optimal action sequence developed by the instructor. The classifications were made in terms of the failing decision function and the cause of the error following a method developed 
at Risø by Hollnagel and Rasmussen (1981). When we, next, briefly show some of the results of these experiments, it is to note that the method does not include an evaluation of the consequences of the committej errors. Thus, the scope is rather the failure mechanisms themselves than the effects of the failures. The method also reveals all errors; $i . e$. it does not take into account that the crew might have corrected them in a real situation.

\section{$\underline{\text { Results }}$}

In the analysis of our results, the following steps are taken: First the total distributions of the errors of both experiments are presented. Then, a comparison between experiment $I$ and II regarding the error distribution is made. Task complexity is the interesting independent variable in this comparison.

In the second step, the occurrence of errors in the action sequence and characteristic differences among the crews' error profiles are analyzed.

In the third step the groups of low and high error crews are collected and their error distributions compared. Also the consistency of the cre'vs' performance in the two experiments is analyzed.

In experimeni I (lea's in the 1 ive steam manifold), 57 errors were identi:ied. As in some cases more than one classification seemed necessary and because no identirication of their priority was made, a total number of 73 classifications was tested in the analysis. The number of errors per crew varied from 3 to 9 . In experiment II (break of the primary manifold of the steam generator), 155 errors were identified varying from 9 to 19 per crew.

The error distributions classified by failing decision function and error type are given in Appendices 1 and 2. The distribution of errors along the decision function was first analyzed. In both 
experiments, the majority of errors concentrated on the decision and execution functions. In the first experiment the corresponding percentages were $31 . \%$ and $48 \%$ and in the second, $40.6 \%$ and $36.8 \%$. The distributions were not statistically different.

Then the distributions along error causes were analyzed using broader error categories (see Appendices 1 and 2). The comparison between the distributions of the two experiments is shown in table 1.

Our results show that deficiencies in process and system knowledge are an important failure cause in disturbance situations. As can be read in table 1 , the proportion of these failures grows with the complexity of the disturbance (experiment I transient is more straightforward and physically transparent than experiment II transient).

The second important result shown in the table is that in a complex situation, deficiencies in communication and cooperation cause proportionally more failures. The growth is small and its significance has to be studied further.

The proportion of procedure related failures is high in the first experiment and strongly reduced in the second experiment. Also this result needs further explanation. It is also important to note that the "simulator effect" is approximately $10 \%$ in these experiments.

In the second step of the data analysis we tried to gain closer contextural knowledge of the failures than the distributions could give. Thus it was studied where in the expected action sequence the errors occurred. These data are given for both experiments in Appendices 3 and 4.

Two things can be found out from these charts. First, there are certain phases of the transient in which errors seem to be concentrated. 
Table 1. Comparison of the error distributions of experiment $I$ and II regarding the error cause categories. Distributions differ significantly $(p<0.01)$.

\begin{tabular}{|c|c|c|c|c|}
\hline \multirow[t]{2}{*}{ Error Categories } & \multicolumn{2}{|c|}{ Experiment I } & \multicolumn{2}{|c|}{ Experiment II } \\
\hline & $\mathbf{n}$ & 8 & $\mathbf{n}$ & $x$ \\
\hline 1. Control room layout & 4 & 5.5 & 5 & 3.2 \\
\hline 2. Procedures & 22 & 30.1 & 27 & 17.4 \\
\hline 3. Cooperation & 10 & 13.7 & 25 & 16.2 \\
\hline $\begin{array}{l}\text { 4. Knowledge and action } \\
\text { control }\end{array}$ & 25 & $34 \cdot 3$ & 86 & 55.5 \\
\hline 5. Action disturbance & 4 & 5.5 & 0 & 0 \\
\hline 6. Simulator effect & 8 & 11.0 & 12 & 7.7 \\
\hline & 73 & 100.0 & 155 & 100.0 \\
\hline
\end{tabular}


As an example in experiment II, which was a LOCA-transient, a concentration of errors could be found as shown in Appendix 4 . In the stabilization phase, particularly after initiating an additional failure, many errors were committed. Critical tasks in this part of the sequence were decreasing of the primary pressure and simultaneously maintaining the boiling margin. As the table indicates, there were many errors in this part of the phase.

For example, step 17 can be considered as the key action in attempting to reduce primary pressure. Seven errors were committed there. The causes of not adequately starting the use of normal makeup water system were communication and strategic (E, G, I) and, in other cases, problems of procedure and knowledge deficiencies $(H, K)$.

The frequency of errors in step 18 was even higher. This step can also be considered important in reducing primary pressure. Crews $A, B$ and $L$ performed the required measures but they were delayed. Crews $C, D, E$ and $G$ omitted the measures eventually because they were not included in the procedure. The procedures that were valid at the time of the experiment were rather general including only 12 steps.

The steps 23-26 are the last of the stabilization phase. As to its physical nature, it is perhaps the most complicated phase in the atcle transient. The main goal here is to hold the boiling marin, i.e. the pressure and temperature should be lowered in synchronization as to avoid boiling of the water. In this phase, the so-called TMI-phenomenon appeared. In it, the pressurizer fills up with water because of heavy evaporation of water in the reactor and formation of a steam bubble. This phenomenon caused problems, which are reflected by the errors in steps 23-26. Al1 but one crew (L) committed errors in these four steps. Their causes are distributed in the following manner: action control (11 $=50 \%$, particularly delays and lack of supervision), cooperation $(7=31.8 \%$, particularly lack of common strategy), procedures $(3=$ $13.6 \%)$ and layout $(1=4.6 \%)$. Thus, we notice a high rate of 
action control deficiences and a rise in the rate of cooperative problems in this difficult and critical point of the transient.

The second important observation in this analytical step was that there are clear differences between the error profiles of the crews. As a starting point, we analyzed the crews' performance in the initial diagnosic phase of the transient of experiment $I$. There appear typical differencies on the way the crews judge the situation and their reeds. These differences can be used as a basis for grouping the crews into three types.

The first group was identified as the one having problems in diagnosing the situation (see Appendix 3 ). This was the case in three crews (E, F, G). These crews were using instructions but, at least in the beginning, there occurred problems in their selection.

The second group comprised those crews which made a right diagnosis and also used instructions (A, B, C, D).

There was also the case in which the crew during the second, initial diagnosis phase of the transient made the decision not to use instructions. This crew $(H)$ was considered as a third group.

It was typical for the first gioup of the crews that diagnostic problems occurred also in the later phase of the transient as Appendix 3 shows. Characteristic for these crews were also errors caused by deficiencies in procedures. The second group of crews had some problems related to deficiencies in knowledge of the processes and systems. Even though they also used instructions, there were almost no errors caused by deficiencies in them. The third group of crews was represented by only one crew, $H$. As mentioned, typical of this crew was the conscious neglect of the instructions.

The performance of the second crew was better than the other two groups according to the overall error rate. 
In the case of experiment II, the success in the initial diagnostic activity did not predict later success in the performance. This might be due to the nature of the transient. Instead, we took the third step in the analysis and split the crews of the second experiment in two groups according to their performance measured through weighted error rate. The result of comparison between the low and high error crews according to the error cause is presented in Table 2.

Interesting in this comparison is that the procedure-caused errors and cooperation errors are proportionally higher for the high error crews. This causes eventually the significant difference between the distributions.

Finally, it is interesting to see how those crews that succeeded well in the first transient would do in the second one, and how those who were less successful in the first would manage in the second. A consistency in the crews' placement in the two groups (low and high error) wouid be needed for formulation of a hypothesis that there were some habitual factors that would explain the differences in the crews' performance. A comparison of the crews' placement into the different groups is given in Table 3 .

\section{Conclusions}

Our data and the instructor's notes during the experiments show that the deficiencies in process and system knowledge are important failure causes in disturbance situations. The proportion of these failures grow with the complexity of the disturbance. Moreover, the crews seemed to have difficulties to formulate a common strategic plan of managing the situation which would have helped to coordinate their activity.

The crews have tools to use in disturbance and emergency situations. However, our results shows that objective deficiencies in procedures cause failure in handling the situation. There are 
Table 2. Comparison of the error distributions of the low error and high error groups in experiment II regarding the error categories $(p<0.05$ ) (low error $=5$ crews, high error $=7$ crews).

Error Category

Low Error

37

4. Knowledge and action control

5. Action disturbance n

1

5

5

67.3

9.1

$20 \quad 20.0$

0

0

$7 \quad 12.7 \quad 5$ 100.0

High Error

n 8

$4 \quad 4.0$

$22 \quad 22.0$

100
5.0

100.0


Table 3. Crews' placement in low and high error groups in experiment $I$ and $I I$ (crews $J, L, I, K$ were included only in experiment II).

Experiment I

Experiment II

Low error

A

B

C

A

B

J

D

C

High error

$\begin{array}{lll} & \text { D } & \text { I } \\ \text { E } & \text { E } & \text { K } \\ \text { F } & \text { F } & \\ \text { G } & \text { G } & \\ \text { H } & \text { H }\end{array}$


more typical for those crews who, according to the overall failure rate, seem to perform less optimally, as is shown in Table 2. The table also shows that the high error crews have a higher rate of cooperation errors. This reflects problems in forming and communicating a common strategic plan, which could be considered the crucial tool in the more complex situation. The cooperation problems were for all crews most frequent in the critical and difficult phases of the transient. Hence, there are indications of knowledge deficiencies although the operators are well qualified. There are communicational lacks tied with cooperation problems although the crews have worked together a long time. Means that the operators have are not adequately mastered and problems arise in creating new collective means, strategic plans. Problems arise for the same crews and they are in general more frequent in a more complex situation.

Our hypothesis is that all the potentials in the empirical judgement have been used and there is a need for a qualitatively higher level for mastering the demands. Unfortunately, the data do not allow us to test this hypothesis. The method itself finds its limits here: no contextual data of the thinking processes or orientation basis of the operators were collected. Moreover, the scope of analysis is incomplete. In terms of A. N. Leontjer's hierarchization of activity (1979), the method considers process operation merely on the action level, e.g. as fulfilling tasks or solving problems. It excludes the level of activity which is defined through the motives of actions and is needed for deriving the actions. Thus, it is impossible to investigate to what extent motives and the grounds of actions have become conscious and actual determining factors of operators' performance control.

The next step we found necessary was a training intervention study in which an in-depth analysis of the diagnostic activity was carried out. This we realized in the form of a case study with one crew. In this we aimed, first, to acquire knowledge of the operators' actual models of the process. This was realized through training sessions which included modelling tasks as test tasks. Secondly: through analyzing the crews' video taped performances in 
three disturbances, we acquired data of actual performance. Thirdly, by allowing the operators to comment about their own performance, we could get data of the explanative or reflective side of the activity. Through analyzing these levels of knowing, doing and explaining and through contrasting them with each other, we think we will be able to identify contradictions and deficiencies which form barriers in activity. These should be removed. These data are presently under analysis.

Nature of Human Reliability in the Light of the Results

According to our approach, developmental analysis is a necessary means to reveal the essential nature of the research object. This applies also to the problem of reliability. Human reliability is presently conceptualized as "component reliability", which can be defined as the probability of performing the demanded task in a given time. Behind the concept, there is an interpretation of operation work as fulfilling given tasks. This is, however, not the essential nature of the work in complex systems. In terms of differentiating between empirical and theoretical judgement, it could be suggested that the prevailing reliability concept captures the empirical but not the theoretical judgement activity. There would thus be a need to analyze the concepts of reliability and $r i s k$ in their relation to the developing technology and test their validity in complex man-machine systems.

In our psychological analysis, we define human reliability through "parameters" that characterize the mastery of work. The three main parameters are thinking, motivation and cooperation. Enhancing reliability in work would mean a simultaneous improvement in all of them. Our starting point is that high reliability prerequires mastery that exceeds the normally sufficient level, i.e. the operators should be qualified to principally produce the algorithmic or automated performance that is normally required. This is closely related to motivation and responsibility. If the objective cognitive scope of work is split into acts and tasks, 
there are no prerequisites for developing a sense of responsibility over the production as a whole.

The reliability of actions is dependent of the way they have been learned. If rules and routines are acquired in ready form and given, their applicability cannot be questioned during later use. In case of possible errors, the recovery is more probable if the operators possess means to reflect upon their own activity. Conscious creation of activity structures develop these means. 
A'PENDIX 1. Distribution of errors in experiment 1

Error categories

Ixeision function ous dia dec exe fo n :

1. Control room lay out

1

1

separaled displays and controis

12 unclear lay out of panels

I 3 displays difficult to understand

14 information missing

$\begin{array}{lll}3 & 3 & \\ 4 & 4 & 5.5\end{array}$

2. Procedures

21 error in procedures

22 deficiencies in procedures

23 contradictions in procedures

24 procedures not used

$\begin{array}{rrrr}6 & 2 & 8 & 11.0 \\ 5 & 1 & 6 & 8.2 \\ 2 & 6 & 8 & 11.0 \\ 13 & 9 & 22 & 30.1\end{array}$

3. Cooperation

31 insufficient concentration

32 insufficient communication

33 unclear division of lasks

34 lack of operational strategy

$\begin{array}{rrrrr}3 & 2 & 1 & 1 & \\ & 3 & & 6 & 8.2 \\ 3 & 5 & 2 & 10 & 13.7\end{array}$

4. Knowledge and artion contrul

41 insufficient process knowledge

42 inaccurate diagnosis

43 incorrect action

$\$ 4$ omission

45 delay in decision or action

$\begin{array}{llllll}1 & & 5 & 3 & 0 & 12.3 \\ 1 & 3 & & 1 & 5 & \\ 1 & & & 8 & 9 & 12.3 \\ & & & 2 & 2 & \\ 3 & 3 & 5 & 14 & 25 & 34.3\end{array}$

5. Action disturbances

51 external disturbance

52 stress

53 operator incapacitated

$\begin{array}{llll}2 & 1 & 3 & \\ 1 & & 1 & \\ 3 & 1 & 4 & 5.5\end{array}$

6. Simulator effect

61 diffeiences biw. or and simulator

62 at titude towards simulat or

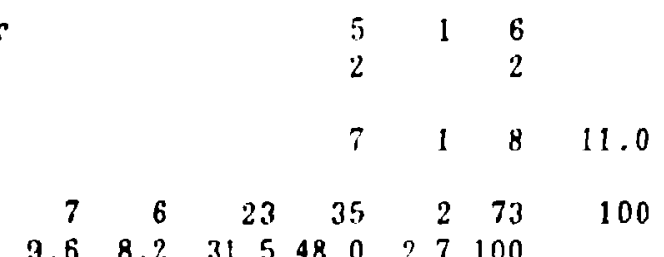

lobs = observation, dia $=$ diagnosis, dec $=$ decision, exe $=$ executiun, $f(b)=$ feedback 
HPtwuIX 2. Distribution of arors in mperinent 11

Error categories laceision fumetion ats atia ase exe fo $n$ s

1. Control room lay oui

11 separated displays and controls

1. unclear lay out of panels

I3 thisplays difficult to understant

14 inf ornation missing

\begin{tabular}{|c|c|c|c|c|c|c|}
\hline 1 & & & & I & $?$ & \\
\hline 1 & & & 1 & & 2 & \\
\hline & & & & 1 & 1 & \\
\hline 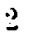 & & & 1 & 2 & 5 & 3.2 \\
\hline$\underline{9}$ & 1 & 5 & 9 & & 17 & 11.0 \\
\hline & & 1 & 1 & & 2 & \\
\hline & & 6 & 2 & & 8 & 5.2 \\
\hline 2 & 1 & 12 & 12 & & $2 \pi$ & 17.4 \\
\hline
\end{tabular}

3. Cooperation

31 insufficient concentration

32 insufficient communication

33 unclear division of tasks

34 lack of operational strategy

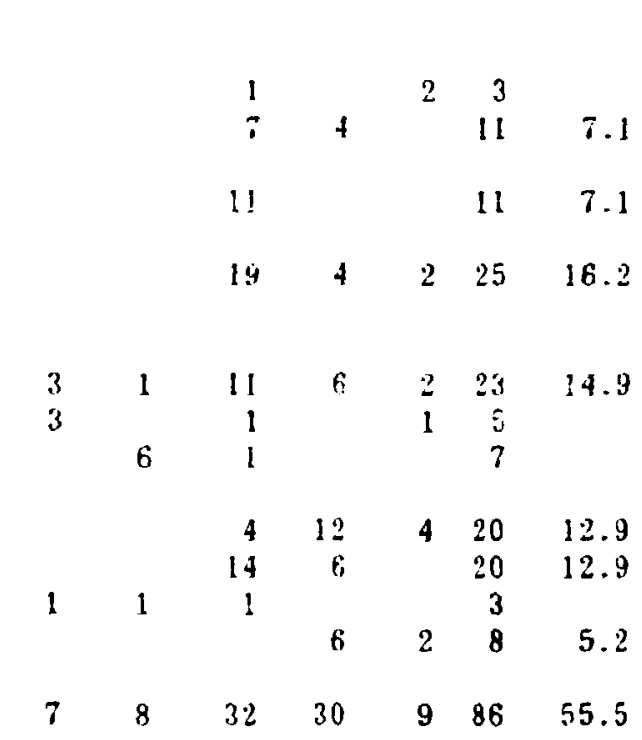

4. knowledge and action control

41 insufficient process knowledge

42 Jeficiencies in processing inf.

43 inaccurate diagnos is

44 incorrect action

45 omission

46 delay in decision or action

47 significance not understood

48 lack of suprivision

5. Action disturbances

51 external disturbanco

52 stress

53 operator incapacitated

0

0

6. Simulator effert

61 differences btw. cr and simulator

62 at litudes towards simulator

$\begin{array}{rrrrrrr}2 & & & 6 & & 8 & \\ & & & 4 & & 4 & \\ 2 & & & 10 & & 12 & 7.7 \\ 13 & 9 & 63 & 57 & 13 & 155 & 100 \\ 8.4 & 5.8 & 40.6 & 36.8 & 8.4 & 100 & \end{array}$

lobs = observation, dia = diagrosis, dec = decision, exe = execution, $f t$ - feeftack 
W'WWIX 3. Uecurrence of errors in artion sequence in experiment :

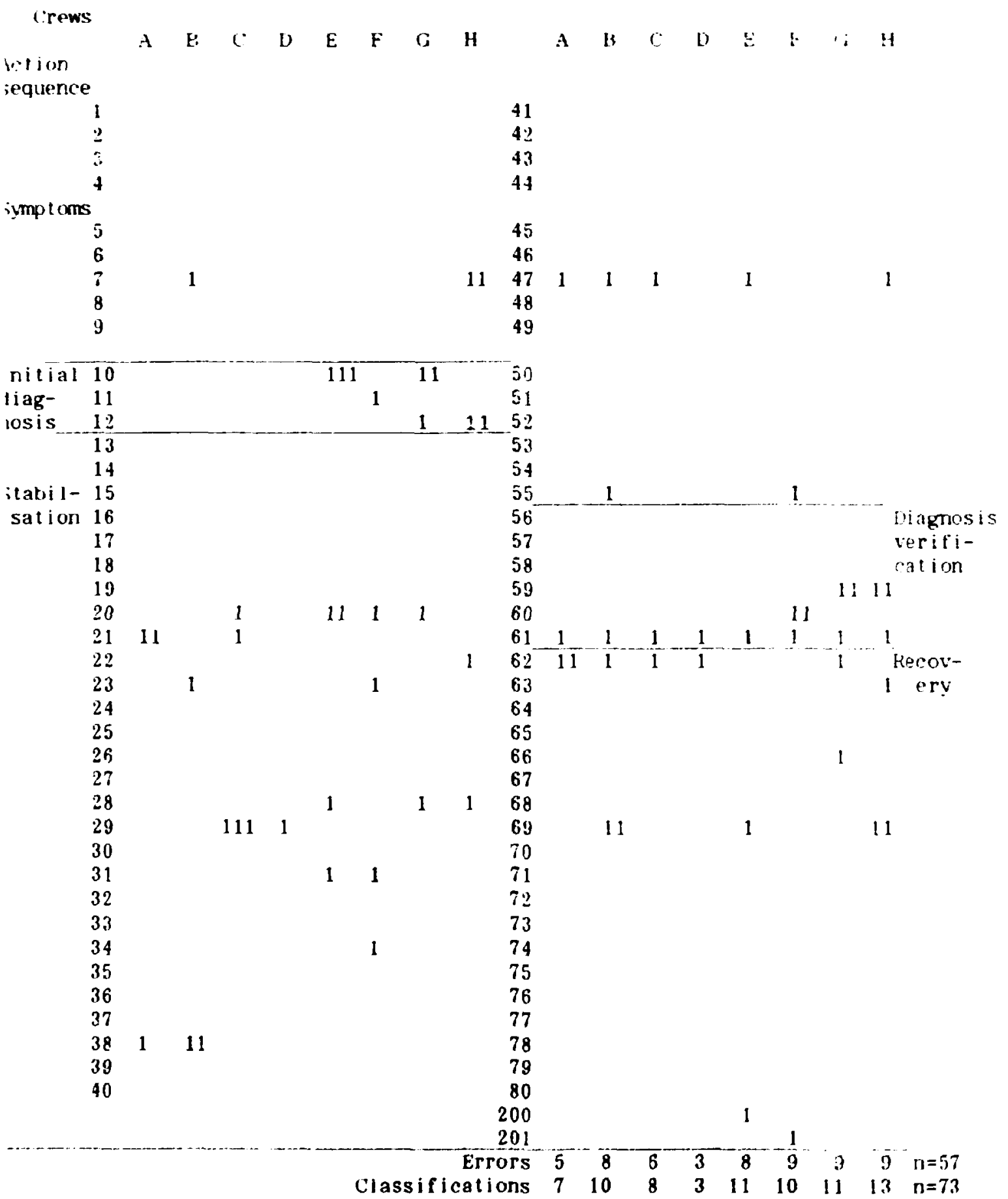


APENDIX t. Occurrence of errors in action sequence in experiment II Crews

Arition

$\begin{array}{llllllllllll}\text { A } & \text { B } & \text { C } & \text { D } & \text { E } & \text { F } & G & \text { G } & \text { I } & \text { J } & K & \text { L }\end{array}$

sequence

symptoms

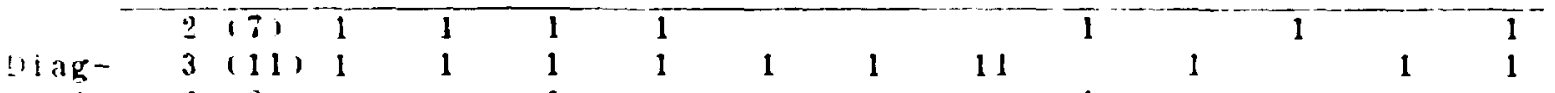

nosis $4(2) \quad 1 \quad 1$

5111

Stabil-

ization $i(1)$

8

1

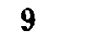

$10(1)$

$11(2)$

12161

13

Addi $-(14,8)$

tiona $15(7)$

dis- 16 (5)

(tero- $17(i)$

ances $18(8)$

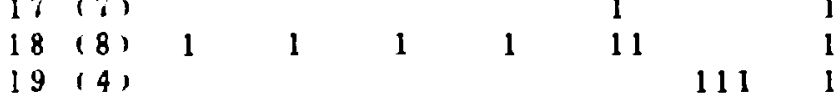

$\geq 0$ (4)

21 (7)

$22(5)$

2318,

$24(4)$

25112 ,

Recov- $\frac{26}{27}$
ery 28

$26 \quad 111$

$23(1)$

$30 \div 11$

31

$32(6)$

33 (5)

$34(1)$

35 (7)

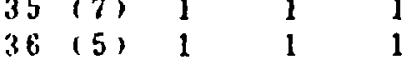

$11 \quad 11 \quad 1$

1

1

- 


\subsection{STUDY OF DIAGNOSTIC RULES BY INTERVIEWING OPERATORS}

\section{Introduction}

Studies at the Halden Boiling Water Reactor and the Lovi isa 2 Nuclear Power Plant were conducted as part of the OECD Halden Reactor Project's joint programme including the Nordic LIT4 effort. The overall purpose was the development of methods for operator training and the collection of human malfunctioning during simulator training sessions.

The basic aim of the work was an investigation of the diagnostic methods used by experienced control room personnel in order to develop a set of diagnostic rules which could aid operators in the diagnosis of transients. Hork along these lines has been in progress for a number of years (Duncan and Shepherd (1975). Marshall et al (1981)). Although such work has been chiefly confined to the petrochemical industry, for the purpose of this exercise, the situation in nuclear power plants was deemed sufficientiy similar to warrant its application here. For example, both endeavors require serious attention to overall goals relating to safety and production and both have processes of comparable levels of complexity which are remotely controlled from central control rooms with similar instrumentation.

In addition to considering the diagnostic methods used, Lovi isa operators were also asked about what amendments and/or improvements they would like to see in the control room to help them in diagnosis.

Lastly, the results of the study have had an effect on portions of the training program implemented at Halden in connection with the experimental programe utilizing the on-site NORS full-scale simulator. 


\section{Diagnostic Rule Generation at the HBWR}

The main objectives of this study were:

- to elicit "rules of thumb" from the operators, either individually or in groups, using a so-called fault Symptom Matrix generated by the senior reactor engineer at the plant.

- to test these rules against the Matrix and modify them accordingly.

- to interview sporators and try ts enlarge the Matrix with additional faults suggested by the operators themselves.

- to use the resulting information as a basis for constructing a short training programme on diagnosis.

As stated, the approach has been used successfully in the petrochemical industry. While the two application areas are not identical - e.g., the nuclear solution is based to a greater degree on formal, written procedures - it was still seen as a useful aid, especially in the early states of a transient where a number of simultaneous things can occur which often lead to erroneous first diagnoses based on misleading or inadequate information. Thus the objective of the approach is the development of versatility in diagnosis so that operators can learn to utilize strategies and rules which will allow them to cope with new and unexpected situations not previously encountered during operation or training.

A Fault Symptom Mutrix is an array of information relating given faults with corresponding symptoms (indications, meter readings, etc.). Fig.7 illustrates such a matrix. Before any discussions were started with the operators, a tentative matrix was constructed in cooperation with the senior st.aff. The set of faults included was of course not exhaustive, but it contained especially important, difficult and/or critical situations which actually had occurred or were feasible. Special thought had also 


\section{FAUI.T SYMPTOM MATRIX HAI.DEN HBWR}

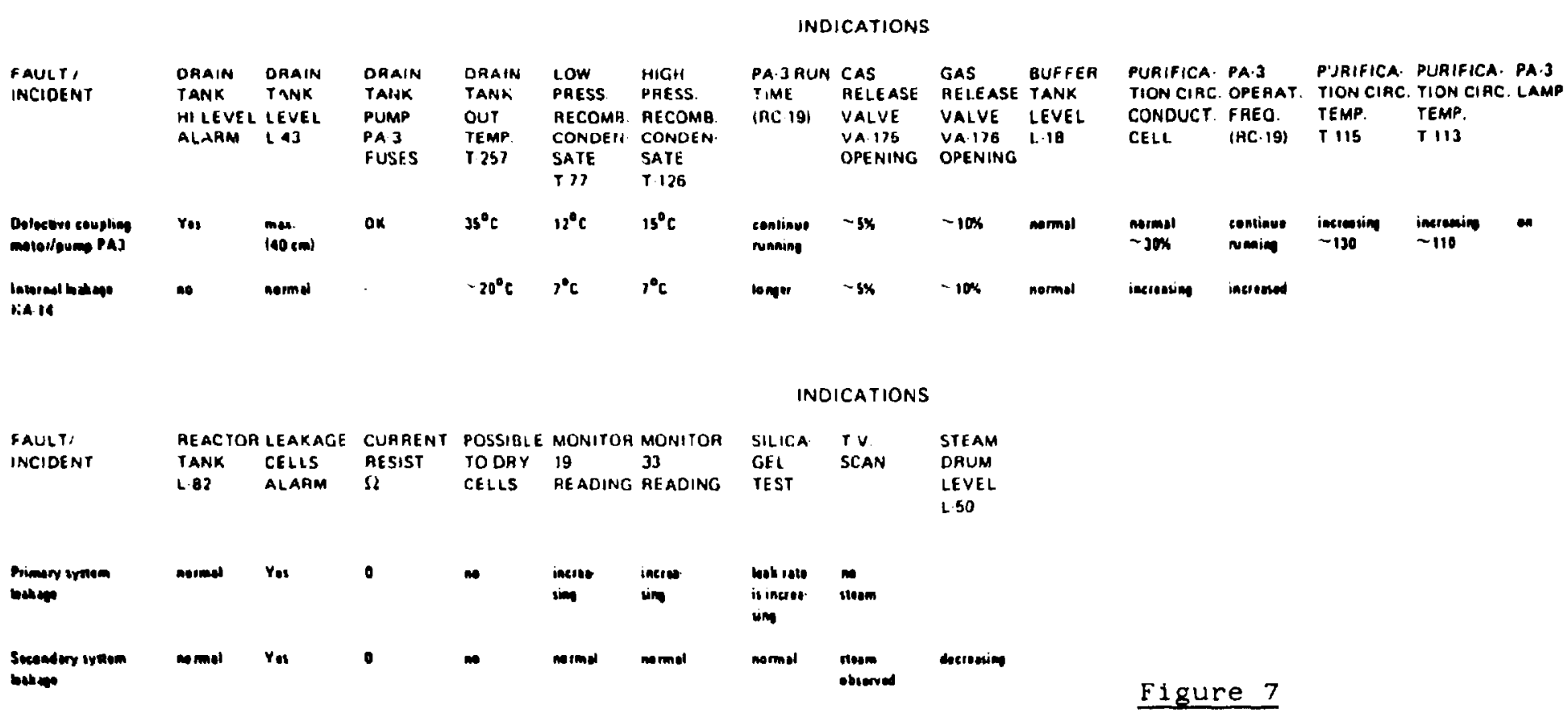


to be given to those faults where the symptom sets were too similar or inconclusive.

The matrix was then used to stimulate an initial discussion with two Halden reactor operators with an eye toward eliciting a number of "rules of thumb" representing the way these operators would go about diagnosing problems in the control room. The questions listed in checklists 1 and 2 were used in conjunction with the Fault Symptom Matrix to assist in the elicitation.

The first draft of rules consisted of the following:

- Look at alarms

- Confirm alarms

- Check appropriate instrument(s)

- Check control loops

- Suspect the instrumentation

A second meeting with two other operators was held to obtain answers to questions which arose after the first meeting and also to expand the circle of interviewed operators and thus obtain a better consensus - i.e., an optimum distillation of available expertise and experience. Specific system-relevant details were discussed. In addition, experierce was stated to be the major prerequisite for being able to evaluate the "gravity" of a disturbance and for anticipating many of the fault situations before they resulted in the triggering of alarms. However, they considered the following set of rules to be applicable:

- Look at alarms (general, loop, heat removal...)

- Confirm alarms

- Check appropriate instruments (depending on the alarms)

- Check relevant control loops including

pumps -.... flows, levels

valves -... open/closed 
Checklist 1

THE FAULT SYMPTOM MATRIX

1. The first step in constructing a fault symptom - itrix is to select a set of faults or incidents which operators need to be able to cope with. This will not be a complete listing of everything which could 90 wrong, but should contain a number of incidents which are thought to be espesially important or difficult to deal with.

2. For each of the faults or incidents chosen above, a list is made of relevant instrument readings and indications. This can include information not directly available in the control room.

3. This information is then drawn up as a matrix:

\begin{tabular}{|l|l|l|l|l|l|l|l|l|l|}
\hline Fault/Incident & \multicolumn{7}{|c|}{ Indications } \\
\hline & & & & & & & & & \\
\hline & & & & & & & & & \\
\hline & & & & & & & & & \\
\hline
\end{tabular}

6. Readings included in the matrix can be detailed, eg. specific temperatures or pressures, or more general eg. high. low, etc. whichever is thought to be adequate.

Should the case arise in which two faults give similar indications, additional time should be spent on finding a means of differentiating them.

5. Operators are thengiven the list of selected indicators (without the readings) and told "something has gone wrong. What information would you look for?" Readings can then be given to the operatcrs as they request them and a careful note is made of the order in which the information is requested. In this way. a step-by-step description can be obtained of the way in which operators work toward a diagnosis.

operators will differ in their strategy, and, at this stage, discussions are held to determine the "best" or generally agreed course. The aim is to arrive at a number of "rules of thumb" which can be applied in dealing with any incident.

6. Once a generally agreed set of rules is arrived at, they can then be tried out on more incidents to determine whether they work and modified accordingly. 
Checklist 2

QUESTIONS TO OPERATORS

(To be used in conjunction with the Fault Symptom Matrix.)

1. Would there be any other alarms with these faults?

2. Are there any other indications you would want to add to this set for each of the faults?

3. Hould the alarms be the first thing you would notice?

4. Presumably, when you get an alarm, it could indicate a number of possible faults. What is the first thing you would check/do?

5. Put another way, what is your first priority when you get an alarm?

5. What other fauls/incidents do you think it would be useful for a new operator to know? could we have a Fault Symptom Matrix for these?

7. Can you think of any faults or incidents which are very difficult to separate from each other because the indications they give are so similar?

If yes:-

What are they?

What are the indications?

How would you separate them? lie. What

additional information would you look for to distinguish between them?

8. How useful are the alarms? Hould it help to nave some kind of filtering system for alarms especially during scheduled actions like start-up where you have a lot of alarms just as a result of this particular procedure?

9. Are there things you would do before trying to make diagnosis such as ensuring that certain parameters were within limits.

10. How are tasks divided in the control room:

a) in normal operation

b) in the event of an incident?

Note: These are questions which seemed useful and relevant to ask the operators at Halden. They would, of course need to be modified in other situations. 
pressures

temperatures

- BEGIN to suspect the instrumentation

The formulation of the last rule differs a bit from the first version in that it attempts to counteract the tendency to begin by regarding any disturbance as a probable instrument failure.

In addition, several more general operating strategies were elicited which provided a broader guidance for work in the control room. These were:

- Never assume at the start that the problem is due to an instrument failure.

- Always take alarms seriously

- Any leakage alarm is serious

- Any increase in concentration on gas monitors is serious

- If unsure at any state, ask for hflp

The study at Halden was felt to be a useful exercise and provided a good basis for the following work. Generalisations of course can be difficult to make - some of the above items are quite plantspecific. However, the method seems to be feasible in nuclear power plant applications and a rule generation exercise is planned as part of the diagnostic training program for the NORS simulator. See this section.

\section{Study at the Loviisa 2 Plant}

This study was conducted in the form of an interview with an experience shift supervisor in order to ticit his opinions on process fault diagnosis in (existing) control rooms with regard to instrumentation, information presentation, etc. together with 
suggestions for modifications, improvements. More detailed objectives were:

(1) Conduct a "structured" interview with an experienced staff member with a view to eliciting information on the problems involved in running a plant under both normal and abnormal conditions.

(2) Discuss the role of operating procedures.

(3) Consider the use of instrumentation in the control, especially with regard to the presentation of information to the operators.

(4) Note any suggestions for improvement in any of the above based on practical operating experience.

(5) Elicit suggestions which might be incorporated into a training programme for operators, such as that for the NORS simulator at Halden.

Regarding (1) and diagnosis, the location of a leak was used as an example. A number of important steps must be gone through:

\section{STEPS IN LOCATING A POSSIBLE LEAKAGE}

1. WHERE is it?

2. How BIG is it?
Primary or Secondary

Inside Containment or Outside

(If inside, the moisture

content will rise together

a change in underpressure)

Try to shut down or isolate

Pressure level goes down

(with only one feedwater

pump as is normal) 


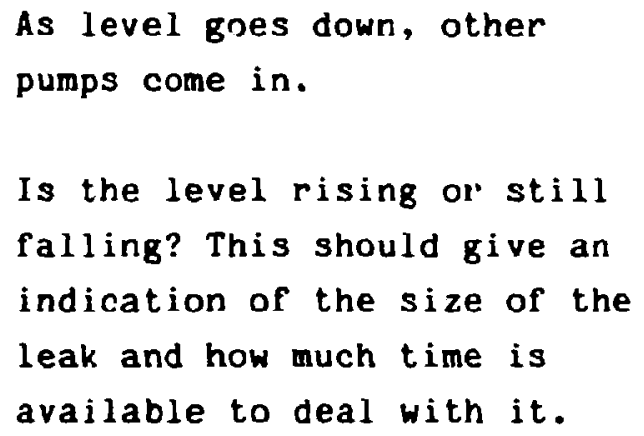

3. Get warm water in How big are the pumps?

What are they capable of?

(There may be sufficient water but it may not be possible to pump it efficiently under abnormal conditions)

Regarding the type of information presentation best suited for specific purcoses, the opinion was that there was at present too much information on the VDU's and that it would better to have "pre-processed" information. Indeed the diagnostic rules at Loviisa were felt to be of the type which assisted operators in breaking down the vast array of information into a form which is both comprehensible and easy to utilize - often under difficult circumstances.

In addition, it was felt that the computer could be used to direct the operator to approprate information and instruments which he then could verify. It was critically important that the main plar.t parameters were displayed prominently. Information retrieval was seen as a problem - e.g., if pumps are started from one location but have to be controlled from another panel - conflicts also can arise between using the VDU displays and the dedicated instrumentation and indicators.

The need for overview displays in the form of a mimic of the process diagram on a VDU was expressed. The operator could 
interact directly with the diagram via a light pen or touch panel and thus receive feedback from the computer to indicate that the appropriate actions had been taken and the proper responses made by the system. Overall status could be gotten at any given time. It was feit that such an approach would facilitate transfer of operators from one plant to another of the same type.

The computer could also be used in a more comprehensive way to support the operator. Examples mentioned were concerned with displayir.g safety system status as well as interlock and protection system status during startup, etc. In addition, the whole area cf computerized operating procedures would appear to be a relevant area to study.

Dependence on computers and their reliability was not seen as a special problem. The suggestion was made that, if there were no expenditures made on conventional panels, it would be possible to invest in more computer back-up. The (un)reliability of conventional kncbs and switches was also pointed out. However, there is a potential disadvantage in forcing operators to sit for long periods of time looking at VDU. This could be overcome to sume extent by having a small number of selected wall-mounted instruments displaying the main parameters; these would permit the operators to move about the control room while keeping in touch with the overall status. They could then return to the VDU for control purposes and the retrieval of additional information. A consideration of shorter shift periods could also be made.

There was expressed enthusiastic support for colour displays, since, for example, this would allow the main process parameters to be colour-coded, thus increasing their visibility.

The use of full-scope simulators was supported seen from the point, of view of being able to replicate incidents from the station control room and hold "post mortems" on the actions actually taken so that assessments could be made and alternate solutions evaluated. 


\section{Operator Training and Simulator Fidelity}

An important element in a training programme is the use of sirulation. A major concern is the selection of one or more levels of simulation ridelity appropriate to different aspects of the training. See also Baker and Marshall (1983) and Rouse (1982, 1985) for further discussions of this point.

Since this report deals with training for diagnostic skills, a few remarks will be made relating fidelity to training for unusual events. As an argument for utilizing full-scale simulators, it is stated that gaining experience with unusual process events on a simulator will improve operator performance when faced with a real event. It may be possible to demonstrate that this is true when previously practised events do actually occur in the control room. However, the object of training should be to prepare the operators for events which have not been foreseen and thus not experienced in training situations cal a simulator. To be able to be versatile in coping with suoh disturbances, the operators need general strategies which often involve collation and interpretation of a large array of information. Although such skills can be (and probably have to be) tested using full-scale simulators, there is little to be gained in teacling them in such an environment.

Thus much can be said for adopting 3 mixed-fidelity approach to training - i.e. an amalgamation of a number of instructional techniques which utilize simulation on at least three different fidelity levels - low, medium and high. Low fidelity simulation can be employed to teach basic skills, principles and coricepts. A more intermediate level can be used for applying these basic skills to the type of equipment being simulated while the final full-scale simulator can provide practise on almost the "real thing" and, at the same time, provide a test bed for performance evaluation. 


\section{NOAS Training Progran}

The development of the NORS facility at Halden, with its demands for a team of skilled operators has highlighted the importance of training in the Halden research programme. Considerable efforts have been devoted to the construction of a documented, modular training programme which emphasizes self-instruction combined with close monitoring of each student's progress. The programme was specifically devised to irtroduce volunteer operators to the NORS process in preparation for their participation in various experimental and evaluational projects. Interest in the development and testing of computerized operator support systems necessarily involves the training of operators to cope with infrequent events with the help of new and advanced information display systems.

There are a number of general requirements which had to be fulfilled by the training programme. For example,

- the programme had to be designed so that it was consistent among the various trainees - i.e., it is important that all subjects taking part in the experimenis have been exposed to the same training information and have achieved some common level of competence. In particular, it is important that the material is robust and remains effective over time and with change in instructors.

- the programme had to be tailored to fit into the constraints of a restricted time schedule - which may vary from occasion to occasion. This means that the programme must be flexible and usually highly concentrated and specifically tailored to the experimental goals and requirements.

- the programme had to take into account the number of trainees available, the crew size, etc. This is important in selecting appropriate audio-visual aids, simulator time, etc. 
A typical set of training objectives, in this case used in conjunction with experiments with alarm systems, aimed at training the operators to be able to:

- understand the process

- monitor the plant during normal operation

- manage a load change

- run the plant successfully with partial shutdown

- manage a scram

- recognize transients from disturbed plant conditions

- take the first steps in appropriate remedial actions

- understand the functioning of the automatic protection system

- use the available alarm systems.

The main guiding principle underlying the training programme was that it should be both systematic, well-structured and adequately programmed - taking into account the limited time available, yet ensuring that all trainees received the same information

Programmed instruction aims at enhancing learning by actively involving the student and by organizing the materials and training sessions and incorporating "steps" in the instruction which are gradual and yet steep enough to involve some effurt. This point is especially important when experienced cperators are the trainees. Extreme care must be taken to design the training so that, at every stage, the trainee has to think about what he has been taught and apply any newly acquired knowledge in meaningful exercises. Therefore the training was broken down in short periods of concentrated instruction followed by appropriate exercises, simulator practise and discussion so that eventual problems could be clarified.

Considerable reliance was placed on "self-tutoring" and "learning by doing" since, because of the limited time available, it was essential that the trainees could acquire as much practical experience with the NOAS simulator as possible. 
Actually from providing the trainees with an introduction to the simulator, there was a considerable interest in encouraging the trainees to assist in the construction of the programme itself. Trainees were urged to generate their own training material and make suggestions for amendments and improvements.

The main course modules and timetables for the particular training programme under discussion were the following:

MAIN COURSE MODULES

- Introduction and familiarisation

- Detailed plant geography

- Process operations and transient management

- Process fault finding
DAYS 1 15

More information on these modules can be found in Baker * Marshall $(1985 a, b)$. However it is relevant in the present context to describe in more detail the three day course on PROCESS FAULT FINDING.

\section{Training Module on Process Fault Finding}

The objective of this module was that operators should become capable of diagnosing plant failures with a reasonable degree of versatility. Since the particular experiment was an evaluation of an alarm handling system, particular attention was focussed on the use of alarms as an aid to diagnosis. The instruction in faultfinding contained both static and dynamic exercises as described later. 
A powerful technique for teaching the interrelationships between different process systems and thereby also practising the crucial elements of fault-finding is to use sympton generation and/or prediction exercises. This involves asking operators to describe the symptoms they would expect to see in the case of specific plant disturbances. This is, of course, the reverse of the situation in the control room where the operator is confronted with an array of symptoms and is expected to deduce the cause of the disturbance. Nevertheless the generation/predic, ion approach has been shown to be a valuable means for assessing and externalising the way in which operators (and trainees) develop an understanding of the complex relationships between the process and the associated indications (See Marshall et al (1981)).

Two sets of practise faults, each including seven faults, were generated together with associated plant indications. Each crew was assigned one fault from the first set and asked to predict which alarms they would expect to see as a result of this fauit and whether a scram or turbine trip would occur. Each crew explained its solution for the other crews and, after further discussions, appropriate revisions were made. The transient was then run on the simulator and a corresponding alarm list generated. Each crew compared its own list with the simulator output and produced a new 1 ist which, in its view, represented the most important and relevant alarms for the particular fault.

Overhead projector slides were then prepared of these predicted symptom 1 ists.

These slides were used to test trainee operators' fault-finding ability through a series of so-called static diagnostic tests. Each slide was shown for 30 seconds during which time, the displayed problem had to be identified. At the start, as an aid, they were given a list of possible faults from the original sets. These tests are called static because the array of symptoms is fired and does not change with time as would be the case in the control room or on the simulator. As such, the static symptoms 
represent a kind of alarw "signature" for the particular transient.

Initially two static tests each with ten transients were run. After the second test, the syaptoa generation procedure was repeaced for the second set of seven faults. Subsequently two additional static tests combined faults frow the two original sets ( 14 in al1) and were interspersed with remedial practise sessions. The average results across the fourteen trainees are sumarized in the following table:

nesults of STATIC dIAGwostic TeSts

Test 1 Test 2 Test 3 Test 4

Set $A$ Set $A$ Set $A$ Set $B \quad$ Set $A$ set $B$

For all

$\begin{array}{lllllll}\text { trainees } & 838 & 998 & 998 & 348 & 998 & 908\end{array}$

These static exercises thus served the purpose of focussing the trainees" attention on the alarm displays. They were followed by djnanic exercises on the sinulator. Each crew took a turn at the simulator and a transient was initiated. The crew then attempted to diagnose the problem and take whatever remedial action was necessary. There was no formal scoring - although all crews made successful diagnoses. No interference was allowed from the other trainees; however there was a discussion afterwards. In order to have a set of unseen transients for the subsequent experiment, twenty transient scenarios were prepared. Eight were used as practise transients during the dynamic exercises.

There turned out to be delay between the original training course and the start of the experiments. Therefore, it was felt neccssary that the volunteer crews attended an extended period of retraining prior to the experiments. This refresher course consisted of both classroom exercises and hands-on simulator practise. Several aspects of crew performance were carefully reassessed - in particular the retention of process knowledge and faul-finding 
ability. Four days were allocated to this re-training and this period was regarded as the absolute minimum.

With regard to fault-finding performance after the five month pause, the results indicate that, after repeating the static test using the symptom patterns for the original fourteen faults presenied in a random sequence and for thirty seconds each, the average score for the fourteen trainees was 10.2 out of 14 (or 738).

Another retention test required trainees to give their opinions on the consequences of certain plant failures and the appropriate remedial actions to be taken. For example, "what would hapen if the turbine by-pass valve failed to open after a turbine trip? What would you do to remedy the situation?" The average score here was 13.4 out of a maximum of 17 .

The retraining included also dynamic testing with three or four of the original fourteen faults. Some time was used for explanations and discussions among crews about the nature of the failure and the alare patterns which resulted.

\section{Results}

Overall, the training program accomplished its main objective which was the production of a number of crews sufficiently faniliar with NORS to cope with a fairly complex set of experimental scenarios after only a very short training period. A point not to be overlooked is that the crews enjoyed the training and found the course useful. Questionnaire responses showed an increasingly favourable attitude on the part of the trainees as measured before and after the first training period.

Unavoidable delays between the first training period and the experiment necessitated the running of a re-training ccurse. Far from being a difficulty, however, this allowed us not only to refresh the trainees' knowledge of MOAS immediately before the 
experiment but also provided an ideal opportunity for measuring retention of the material learned and chus of assessing the efficacy of the training.

Taken as a whole, the training material prspared so far serves as a good foundation for the further course development. Comments from trainees and suggestions for amendments to course content will also be taken into account. In addition, performance during experiments coupled with test results provides a good indication of strengths and weaknesses in trainees' knowledge. Awareress of this can be very useful in planning and pinpointing future training needs.

Work is already underway on various improvements. A start has been made on the development of a training module dealing specifically with the diagnosis of plant failures and remedial actions appropriate under various disturbance conditions. The aim is not simply to provide training on a specific umber of pre-arranged transients, but to develop generalisable diagnostic skills which can assist the operator in dealing with plant disturbances he has not previously encountered. 


\section{CONCLUSIONS AND RECOMENDATIOAS}

Results were expected in the following areas:

- better knowledge about operator tasks and operator performance in specific situations.

- better methods for training

- a reliable method for data acquisition and operator observation which can be used during regular training

- better understanding of what constitutes effective operator strategies and knowledge as basis for good team performance.

\section{Regarding the control room operators' work situation}

Studies of several crews, each dealing with two incidents of varying complexity on a training simulator, indicated that deficiencies in (utilizing) process and system knowledge seem to be important sources of errors in disturbance handling - as are difficulties which crews experience in formulating a common strategic plan for coordinating their activities in order to cope with the situation. However limitations in the observation method employed did not perwit the collection of data which could lead to actual information on the operators' thinking processes or motivations for action. I.e., the observation was limited to a considerable degree to the surface behavior of the crew on the plant as supplemented by the instructors' and observers' interpretations. Newer studies are attempting to overcoure these limitations.

At the theoretical level, the question of human reliability can be fruitfully handled through "parameters" which characterize the mastery of work - i.e., thinking, motivation and cooperation. The reliability of actions is dependent on the way they have been learned as well as the operators' means for reflecting upor. their 
own activity. For example, a conscious creation of activity structures should enhance the development of these means.

Regarding diagnostic training

It is obvious, both from written and from oral crew member comments, that some kind of supplementary operator support is highly desirable - especially in helping operators cope with disturbed system state situations for which no instructions are directly applicable. As no such operator support has been included in the crew members' previous training, the basic attitude of the participating experimental group members was very positive lowards the diagnostic rule course. In principle, they considered the diagnostic rule methods to he a valuable and important support in disturbed system conditions. The practical circumstances of the diagnostic rule course did not, however, allow for more than $f$ ive hours' diagnostic search training. This is, of course, completely inadequate when trying to lay down search methods based on heuristics, the nature of which are totally different from algorithmic methods. Therefore, it is hardly surprising that the data collection did not show any substantial differences between the experimental and control groups.

Therefore the main result of the study should be regarded as the positive attitudes shown by the crew members towards employing learned heuristic diagnostic rules. It is encouraging that 58 per cent of the crew members had the rules in mind, despite the short duration of the diagnostic search training. Equally encouraging is the fact that 95 per cent of these crew members found the diagnostic rules to be helpful during the transient treatments. This could be regarded as a hint of the potentials of a diagnostic rule course of longer duration.

- Testing of the Fault Symptom Matrix as a vehicle for establishing useful heuristic diagnostic rules proved to be a useful exercise although generalizations to other systems/contexts can be difficult since some of the rules turn out to be quite plant-specific. 
* Studies during the NORS training program of the retention of learned material on fault symptoms after a five month pause gave encouraging results. The original training had consisted of both "static" tests using slides of symptom patterns as well as "dynamic" simulator testing.

\section{Performance observation}

The instructor's observation method based on the developed form could be used routinely in simulator training provided that appropriate and sufficient training of instructors has been $g$ iven. of course this could be altered in different ways to suit various practical circumstances, but the principle of using diagnostic phases should be kept intact. As these phases are based on the normal way of approaching disturbed system states, data concerning the phases will provide a logical and structured analysis of crew performance for the transient de-briefings. The content and presentation of the diagnostic rule course have shown that the nature and application of diagnostic rules can easily be understood by control room crew members. Unfortunately, the restricted course duration made a thorough practical application and evaluation impossible.

As a consequence of the above-mentioned conclusions, future research should be carried out in the following areas of diagnostic search training:

- Pedagogical and training strategy aspects of diagnostic search training. This includes the impact of different cognitive taxonomical levels on training methods and strategies etc.

- Analyses of how algorithmic and heuristic based search rules can be combined, both in training and in practical applications.

- Integration of diagnostic search methods in basic and followup operator training schemes. 


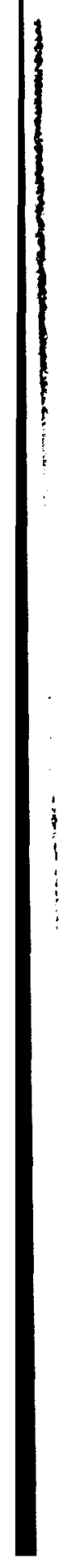




\section{REFERENCES}

Brehmer, B. 1980 In one word: Not from experience. Acta Psychologica, 45, 223-241.

Broadbent, D. and Aston, B. 1978 Human control of simulated economic system. Ergonomics, 21, 12, 1035-1043.

Duncan, K.D. \& Shepherd A. (1975), A Simulator and Training Technique for Diagnosing Plant Failures from Control Panels; Ergonomics, Vol.18, pp. 627-641.

Duncan, K.D. \& Gray, M.J. (1975), An Evaluation of a Fault-Finding Course for Refinery Process Operators; J. Occupaional Psychology, vol. 48, pp. 199-218.

Duncan, K.D. (1981), Training for Fault Diagnosis in Industrial Process Plant; in "Human Detection and Diagnosis of System Failures", J. Rasmussen \& W.B. Rouse (eds), Plenum.

Gagne, R.M. (1965), The Conditions of Learning; Holt, Rinehart and Winston.

Hollnagel, E., Hunt, $G$ and Marshal, E. 1983 Experimental Validation of the critical function monitoring system. Preliminary results of analysis. OECD Halden Reactor Project. HWR-111.

Hollnagel, E. and fasmussen, J. 1981 Simulator training analysis. A proposal for combined trainee debriefing and performance data collection in training simulators. Internal report. Nordiska kontaktorganet.

Hollnagel, E. and Rasmussen, J. 1981 Simulator traininz analysis. A proposal for combined trainee debriefing and performance data collection in training simulators. Internal roport. Nordiska kontaktorganet for atomenergifrogor. Kontrollrummutformning. NKA/KRU-P2 (81) 38 . 
Hunt, R. Rouse, W.B. (1982), A Fuzzy Rule-based Model of Human Problem Solving; Proceedings of the American Control Conference.

Kautto, A. 1984 Information presentation in power plant control rooms. Research reports 320, Technical Research Centre of Finland, Espoo.

Leontjew, A. N. 1979 Tätigkeit, Bewusstsein, Persönlichkeit, Volk und Wissen, Berlin.

Marshall, E.C., Scanlon, K.E., Shepherd, A. \& Duncan, K.D. (1981), Panel Diagnosis Training for Major-Hazard Continuous-Process Installations; The Chemical Engineer, No. 365, pp. 66-69.

Marshall, E. \& Baker, S. (1983), Researching the Role of Simulation in Nuclear Operator Training; Proceedings of Nuclear Facilities Operator Training Topical Meeting, Madrid, Spain, October 19-21, 1983, European Nuclear Society.

Morris, N. \& Rouse, W.B. (1985), Review and Evaluation of Empirical Research in Troubleshooting; Human Factors, Vol. 27 No. 5 pp. 503-530.

Norman, D. 1981 Categorization of action slips. Psychological Review, $88,1-15$.

Norros, L. and Sammatti. P. 1986 (in press) Operator errors during simulator training. Research reports, Technical Research Centre of Finland, Espoo.

Rasmussen, J. (1979), On the Structure of Knowledge, a Morphology of Mental Models in a Man-Machine Context; Risø-M-2192.

Rasmussen, J. (1984), Strategies for State Identification and Diagnosis in Supervisory Control Tasks, and Design of ComputerBased Support Systems; in Advances in Man-Machine Systems Research, Vol. 1, Rouse, W.B. (ed), JAI Press Inc., pp. 139-193. 
Rouse, W.B. (1982), A Mixed-Fidelity Approach to Technical Training; Journal of Ed. Tech. Systems, Vol. 11.

Wagenaar, W. and Keren, G. B. 1985 Does the expert know? NAT0 advanced study institute, Intelligent decision aids in process environments, San Miniato, Italy, September 1985 (proceedings in press). 


\section{LIST OF PROJECT REPORTS}

MKA/L.1TA(83)

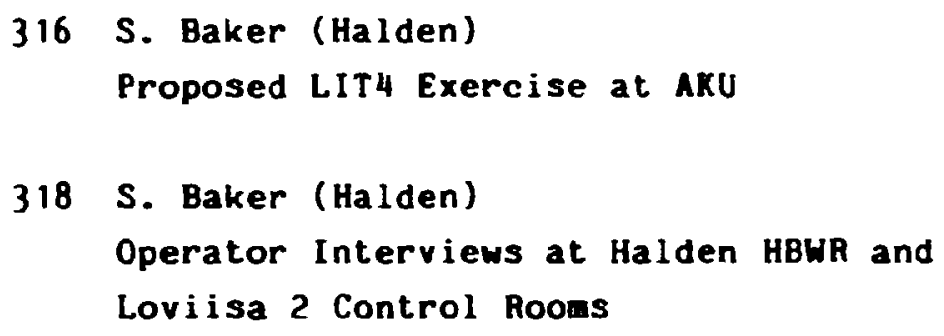

\section{Halden HPR reports}

300 S.Baker E.Marshall

Principles of a Training Programme

for the NORS Simulator (1983)

\section{Halden HW reports}

131 S.Baker

Diagnostic Rule Generation - Operator

Interviews in Nuclear Power Plant

Control Rooms (1964)

136 E.Marshall, S.Baker I.Leikkonen

Introduction to the NORS Simulator -

A Self-tutored Training Programe (1985)

137 S.Baker \& E.Marshall

An Operator Training Programe for Experiments Using the NORS Simulator (1985) 


\section{LIT final reports:}

LIT (85)1 The human component in the safety of complex systems.

LIT (85)2 Human errors in test and maintenance of nuclear power plants - Nordic project work.

$\operatorname{LIT}(85) 3$

organization for safety.

LIT ( 85 ) 4

The design process and the use of computerized tools in control room design.

LIT (85) 5

Computer aided operation of complex systems.

$\operatorname{LIT}(85) 6$

Training in diagnostic skills for nuclear power plants.

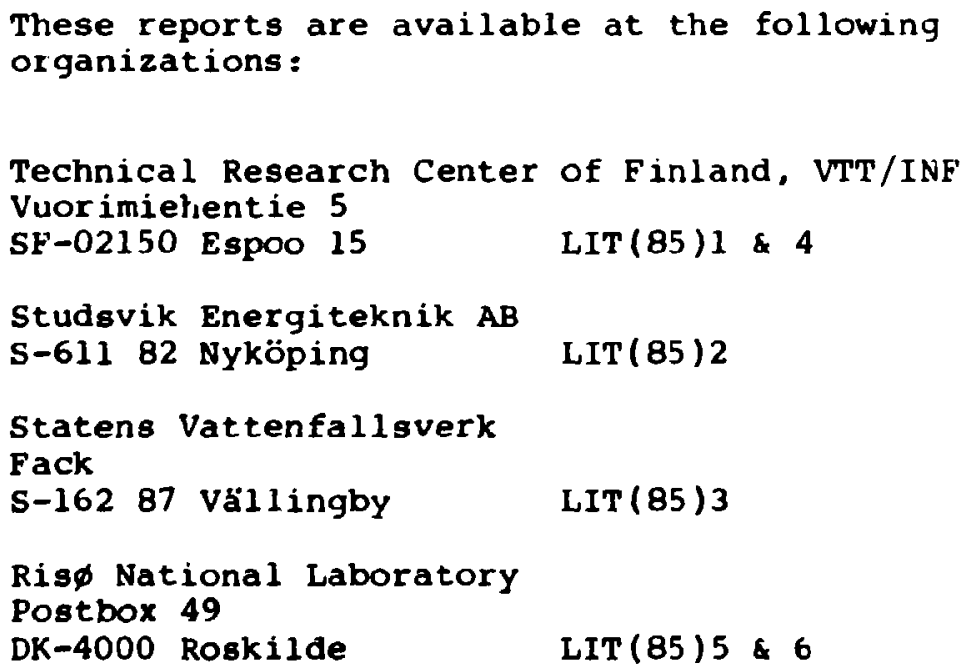

Flandling charge USD 10,- per report to be forwarded with order. 